Thermophysical characteristics and application of metallic-oxide based mono and hybrid nanocomposite phase change materials for thermal management systems

Adeel Arshad, Mark Jabbal, Yuying Yan

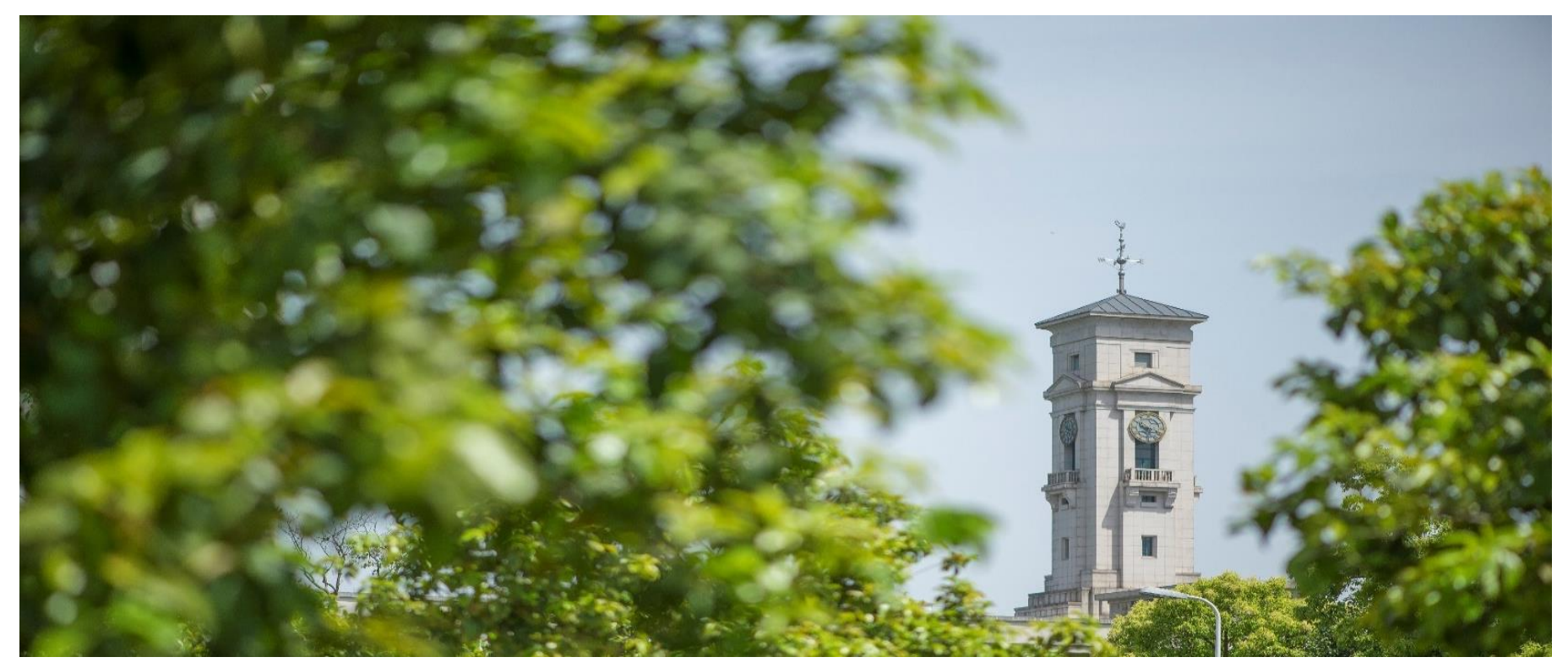


University of Nottingham Ningbo China, 199 Taikang East Road, Ningbo, 315100, Zhejiang, China.

First published 2020

This work is made available under the terms of the Creative Commons Attribution 4.0 International License:

http://creativecommons.org/licenses/by/4.0

The work is licenced to the University of Nottingham Ningbo China under the Global University Publication Licence:

https://www.nottingham.edu.cn/en/library/documents/researchsupport/global-university-publications-licence-2.0.pdf 


\title{
Thermophysical characteristics and application of metallic-oxide based mono and hybrid nanocomposite phase change materials (NCPCMs) for thermal management systems.
}

\author{
Adeel Arshad ${ }^{\mathrm{a}}$, Mark Jabbal ${ }^{\mathrm{a}}$, Yuying Yan ${ }^{\mathrm{a}, \mathrm{b}, *}$ \\ ${ }^{a}$ Fluids 83 Thermal Engineering (FLUTE) Research Group, Faculty of Engineering, University of \\ Nottingham, Nottingham, NG7 2RD, UK \\ ${ }^{b}$ Research Centre for Fluids and Thermal Engineering, University of Nottingham Ningbo China, Ningbo \\ 315100, China
}

\begin{abstract}
This experimental study covers the chemical, physical, thermal characterization and application of novel nanocomposite phase change materials (NCPCMs) dispersed by $\mathrm{TiO}_{2}, \mathrm{Al}_{2} \mathrm{O}_{3}$, and $\mathrm{CuO}$ nanoparticles. A commercial-grade of paraffin, namely $\mathrm{RT}-35 \mathrm{HC}$, was considered as a phase change material (PCM). The mono and hybrid NCPCMs were synthesized at a constant weight concentration of $1.0 \mathrm{wt} \%$. In the first phase, various characterization techniques were used to explore the thermophysical properties and chemical interaction of mono and hybrid NCPCMs. In the second phase, the thermal cooling performance was investigated by filling the prepared NCPCMs in a heat sink at various input power levels. The results showed the uniform dispersion of $\mathrm{TiO}_{2}, \mathrm{Al}_{2} \mathrm{O}_{3}$, and $\mathrm{CuO}$ nanoparticles onto the surface of both mono and hybrid NCPCMs without altering the chemical structure of RT-35HC. The optimum latent-heat of fusion and highest thermal conductivity of $228.46 \mathrm{~J} / \mathrm{g}$ and 0.328 $\mathrm{W} / \mathrm{m} . \mathrm{K}$ were obtained, respectively, of $\mathrm{Al}_{2} \mathrm{O}_{3}+\mathrm{CuO}$ dispersed hybrid NCPCM compared to pure $\mathrm{RT}-35 \mathrm{HC}$. In comparison of RT-35HC, the increasing trend in specific heat capacity was observed of NCPCMs and $36.47 \%$ enhancement was obtained for hybrid NCPCM in solid-phase. The reduction in heat sink base temperature was achieved of $3.67 \%, 6.13 \%$, $13.95 \%$ and $8.23 \%$ for $\mathrm{NCPCM}_{\mathrm{TiO}_{2}}, \mathrm{NCPCM}_{\mathrm{Al}_{2} \mathrm{O}_{3}}, \mathrm{NCPCM}_{\mathrm{CuO}}$ and $\mathrm{NCPCM}_{\mathrm{Al}_{2} \mathrm{O}_{3}+\mathrm{CuO}}$, respectively, compared to RT-35HC. Further, no phase segregation, less subcooling, smaller phase transition temperature, higher chemical and thermal stability were observed with hybrid NCPCMs which can be used potentially for thermal management of electronic devices, Li-ion batteries and photovoltaic (PV) modules systems.
\end{abstract}

Keywords: Phase change material, $\mathrm{TiO}_{2}, \mathrm{Al}_{2} \mathrm{O}_{3}, \mathrm{CuO}$, Nanocomposite phase change

\footnotetext{
* Correspondence authors

Email address: yuying.yan@nottingham.ac.uk (Yuying Yan)
} 
materials, Thermal management 


\section{Introduction}

Energy, Economy and Environment (3E) have the most powerful and urgency importance in current global issues and challenges [1]. Carbon dioxide $\left(\mathrm{CO}_{2}\right)$ emissions, both natural and human sources, has been significantly increasing and contributing a major role in greenhouse and global climate change [2]. Around $87 \%$ of $\mathrm{CO}_{2}$ emissions are due to the human sources come from the utilization of fossil fuels coal, natural gas and oil [3]. Nonetheless, the fossil fuels are still the dominant energy sources for power generation with their share increasing $66 \%$ in 2005 to $77 \%$ in 2050. Therefore, $\mathrm{CO}_{2}$ emissions would increase by $61 \%$ over 2011 levels by 2050 [4. To minimize the $\mathrm{CO}_{2}$ emissions, there is the critical need of alternative and sustainable energy resources to reduce the emerging demand of fossil fuels. With the development of nanotechnology, the heat and mass transfer in nanoconned systems such as nanofluid [5, 6] and nano-composites brings novel insight for energy conversion and storage [7, 8] which make a contribution in thermal management applications. The thermal energy storage (TES) systems based on heat storage materials have been used extensively for energy conversion, storage and transportation in thermal management applications of electronic devices, photovoltaic (PV) modules, Li-ion batteries systems etc. [9, 10, 11]. Phase change materials (PCMs) as heat storage materials meet the series of requirements with higher energy storage density with suitable phase transition temperature range, good stability and low supercooling. For effective heat storage and heat transfer using PCMs, the latent-heat and thermal conductivity are the key thermal properties which improve the thermal management efficiency. Organic PCMs exhibit the best heat storage properties but they have low thermal conductivity which reduces the overall thermal response factor, heat transfer rate and efficiency. Thus, a PCM with higher latent-heat and thermal conductivity with stable chemical structure is the most suitable. To overcome this issue, researchers have introduced several heat transfer enhancement techniques including extruded metal-fins [12, 13, 14, 15, 16, 17, metal-foam and porous materials [18, 19], nanomaterials [20, 21, 22 ] encapsulated micro/nano-capsules [23, 24, 25, 26].

Many researchers are working on different mechanisms for the thermal controllability of structures. Moreover, in addition to PCM there are some other materials that can be used for thermal management system as well as for energy harvesting systems having applications in mechanical and aerospace engineering [27, 28]. Nanomaterials as a supportive materials into the PCMs have taken keen attention in current era due their higher thermal properties and enhance the chemical and thermal stability. For instance, Babapoor et al. [29, 30] 
synthesised the composite PCMs using $\mathrm{SiO}_{2}, \mathrm{Al}_{2} \mathrm{O}_{3}, \mathrm{Fe}_{2} \mathrm{O}_{3}, \mathrm{ZnO}$ nanoparticles and measured the thermophysical properties. They achieved the highest thermal conductivity with 8 wt.\% of $\mathrm{Fe}_{2} \mathrm{O}_{3}$ nanoparticles. However, the authors suggested that $\mathrm{Al}_{2} \mathrm{O}_{3}$ nanoparticles were preferable for thermal management applications. Nourani and his co-authors [31, 32] prepared NCPCMs using $\mathrm{Al}_{2} \mathrm{O}_{3}$ nanoparticles of weight concentrations of 0.5, 5, 7.5, and 10 wt.\% and SSL used as a surfactant to enhance the stability of $\mathrm{Al}_{2} \mathrm{O}_{3}$ nanoparticles in paraffin wax. The effective thermal conductivity enhancement ratios were found of $31 \%$ and $13 \%$ in solid and liquid phases, respectively, at 10.0 wt.\%. Chieruzzi et al. [33] synthesised the mono and hybrid composite PCMs of potassium nitrate $\left(\mathrm{KNO}_{3}\right)$, used as a PCM, by adding $\mathrm{SiO}_{2}, \mathrm{Al}_{2} \mathrm{O}_{3}$ and hybrid of $\mathrm{SiO}_{2} / \mathrm{Al}_{2} \mathrm{O}_{3}$ having 1.0 wt.\%. The best results were obtained with $\mathrm{SiO}_{2}$ nanoparticles with a decrease of $2-3^{\circ} \mathrm{C}$ in onset temperatures and $9.5 \%$ increase in specific heat. Sharma et al. 34] used the $\mathrm{TiO}_{2}$ nanoparticles of weight concentrations of $0.5,1.0,3.0$, and $5.0 \mathrm{wt} . \%$ and palmitic acid as a PCM to prepare the NCPCMs. The highest thermal conductivity and lowest heat of fusion were obtained of $0.35 \mathrm{~W} / \mathrm{m} . \mathrm{K}$ and $180.03 \mathrm{~kJ} / \mathrm{kg}$, respectively, at $5.0 \mathrm{wt} . \%$ of $\mathrm{TiO}_{2}$. Yang et al. [35] prepared the paraffin and palygorskite mixed composite PCM and revealed the melting temperature and latent heat of $54-56^{\circ} \mathrm{C}$ and $132.18 \mathrm{~J} / \mathrm{g}$, respectively. Li et al. [36] synthesised the NCPCMs using calcium chloride hexahydrate $\left(\mathrm{CaCl}_{2} 6 \mathrm{H}_{2} \mathrm{O}\right)$ as a PCM with $\gamma-\mathrm{Al}_{2} \mathrm{O}_{3}$ and measured the phase-change thermal properties. The maximum thermal conductivity was obtained of $1.373 \mathrm{~W} / \mathrm{m} . \mathrm{K}$ at 2.0 wt.\% of $\gamma-\mathrm{Al}_{2} \mathrm{O}_{3}$ nanoparticles. Sami and Etesami [37] prepared the NCPCMs of using $\mathrm{TiO}_{2}$ and paraffin with mass fractions of $0.5,0.7,1,2,3$ and 4 wt.\% with and without SSL used as a surfactant. Results explored the optimum concentration of 3 wt.\% of $\mathrm{TiO}_{2}$ nanoparticles with the $47.8 \%$ increase in thermal conductivity with SSL compared to the pure paraffin. Further, authors suggested that addition of SSL in NCPCMs showed the better dispersion and thermal stability compared with pure paraffin and $\mathrm{TiO}_{2}$ /paraffin composite. Bashar and Siddiqui [38] prepared the NCPCMs using various types of nanoparticles, $\mathrm{Ag}, \mathrm{CuO}, \mathrm{Al}_{2} \mathrm{O}_{3}$ and MWCNTs and added in paraffin wax. A higher heat transfer coefficient of $18 \%$ and $14 \%$ was obtained for $\mathrm{CuO}$ and $\mathrm{Ag}$ nanoparticles, respectively, compared with pure paraffin wax. Praveen and Suresh [39] prepared the composite PCMs using solid-solid neopentyl glycol (NPG) and $\mathrm{CuO}$ nanoparticles for thermal management application. It was found that maximum thermal conductivity and phase change enthalpy of $0.61 \mathrm{~W} / \mathrm{m} . \mathrm{K}$ and $112.4 \mathrm{~kJ} / \mathrm{kg}$, respectively, were obtained at 3.0 wt.\% of $\mathrm{CuO}$. Recently, Li et al. [40] synthesized $\mathrm{MgO}$ dispersed in eutectic carbonate salt 
of $\mathrm{NaLiCO}_{3}$ and studied the thermal properties of light and heavy weight $\mathrm{MgO}$ nanoparticles. The results found that light weight $\mathrm{MgO}$ nanoparticles of particle size $3-5 \mu \mathrm{m}$ had the maximum thermal conductivity of $\sim 5.5 \mathrm{~W} / \mathrm{m} . \mathrm{K}$ compared to heavy weight $\mathrm{MgO}$ nanoparticles of similar size.

The literature reveals that most of the studies focused on the development of NCPCMs used for the high temperature TES applications. The current study focuses on synthesising of new NCPCMs which will be the most suitable for thermal management of electronic devices, PV modules and Li-ion batteries, working under the safe and reliable operating temperature range of $30-40^{\circ} \mathrm{C}[9$, 41]. In addition, the literature indicates that a very little work has been performed on mono and hybrid NCPCMs. Therefore, the present study aims to improve on the thermophysical properties of a commercially available PCM to enhance the thermal performance. The microstructure, chemical and thermal properties are investigated of $\mathrm{TiO}_{2}, \mathrm{Al}_{2} \mathrm{O}_{3}$, and $\mathrm{CuO}$ nanoparticles dispersed mono and hybrid NCPCMs. Further, various characterization techniques were adopted to analysis the surface morphology, chemical and physical interaction, thermal properties including phase-change temperature, melting/solidifying latent-heat enthalpies, specific heat capacity, thermal conductivity, thermal stability and reliability. The newly developed NCPCMs were then poured in a heat sink to investigated the transient temperature thermal response to explore the thermal cooling performance.

\section{Experimental procedure and characterizations}

\subsection{Materials}

In present study, the RT-35HC (a commercial grade of paraffin) was used as a PCM with phase-transition temperature of $34-36^{\circ} \mathrm{C}$, purchased from Rubitherm GmbH, Germany. Three different metallic-oxide nanoparticles such as copper oxide $(\mathrm{CuO})$ (particle size $<50$ $\mathrm{nm}$, surface area: $29 \mathrm{~m}^{2} / \mathrm{g}$ ), aluminium oxide $\left(\mathrm{Al}_{2} \mathrm{O}_{3}\right)$ (particle size $13 \mathrm{~nm}$, surface area: $85-115 \mathrm{~m}^{2} / \mathrm{g}$ ), nano Titanium (IV) dioxide $\left(\mathrm{TiO}_{2}\right)$, anatase powder (particle size $<25$ $\mathrm{nm}$, surface area: $45-55 \mathrm{~m}^{2} / \mathrm{g}$, density: $3.9 \mathrm{~g} / \mathrm{mL}$ at $25^{\circ} \mathrm{C}$ ) were purchased from SigmaAldrich, UK. In all samples Sodium dodecylbenzene sulfonate (SDBS) was used, obtained from Sigma-Aldrich, UK. Table 1 is summarized the thermophysical properties of RT-35HC. All materials were used as they received without further chemical treatment. 
Table 1: Thermophysical properties of $R T-35 H C$.

\begin{tabular}{|c|c|c|c|c|}
\hline $\begin{array}{c}\text { Melting temperature } \\
\left({ }^{\circ} \mathrm{C}\right)\end{array}$ & $\begin{array}{c}\text { Thermal conductivity } \\
(\mathrm{W} / \mathrm{m} . \mathrm{K})\end{array}$ & $\begin{array}{c}\text { Latent-heat of fusion } \\
(\mathrm{J} / \mathrm{kg} \cdot \mathrm{K})\end{array}$ & $\begin{array}{c}\text { Specific heat } \\
(\mathrm{J} / \mathrm{kg} . \mathrm{K})\end{array}$ & $\begin{array}{c}\text { Density } \\
\left(\mathrm{kg} / \mathrm{m}^{3}\right)\end{array}$ \\
\hline $34-36$ & 0.2 & 240,000 & 2000 & 880 (solid) \\
770 (liquid)
\end{tabular}

\subsection{Preparation of nanocomposite PCMs}

The schematic diagram of preparation of NCPCMs is shown in Figure 1. A well-precise two-step preparation method was carried out to synthesize the mono and hybrid NCPCMs, which has been used extensively in preparation of nanofluids [42]. The RT-35HC was used a base $\mathrm{PCM}$ and $\mathrm{TiO}_{2}, \mathrm{Al}_{2} \mathrm{O}_{3}$ and $\mathrm{CuO}$ nanoparticles were used as an additives. The purpose of adding the nanoparticles is to enhance the thermal properties. In first part of NCPCMs preparation, the $\mathrm{RT}-35 \mathrm{HC}$ was melted at a temperature of $70^{\circ} \mathrm{C}$ constantly through a hotwater bath. The SDBS was then added, as a surfactant, into the RT-35HC at fully melted stage with a ratio of $4: 1$ wt.\% of nanoparticles to enhance the dispersion stability. The nucleating agent mixture of RT-35HC and SDBS was stirred vigorously at $450 \mathrm{rpm}$ and kept for 30 minat $70^{\circ} \mathrm{C}$. Thereafter, constant amount of 1.0 wt.\% of $\mathrm{TiO}_{2}, \mathrm{Al}_{2} \mathrm{O}_{3}, \mathrm{CuO}$ and $\mathrm{Al}_{2} \mathrm{O}_{3}+\mathrm{CuO}$ were added separately into RT-35HC and stirring was continued for further 3 hrs to achieve a uniform and stable dispersion of nanoparticles. The mass ratio for hybrid NCPMs was kept $75 \% / 25 \%$ of 1.0 wt.\% to keep the total mass percentage constant. In second part of the NCPCMs preparation, the ultrasonication process was carried out for $60 \mathrm{~min}$ at ultrasonic frequency of $40 \mathrm{kHz}$ [8, 43]. The ultrasonication process improved the stable dispersion of nanoparticles more homogeneously and minimized the sedimentation and aggregation, as shown in Figure 2. The four different samples of the mono and hybrid NCPCMs were prepared and labelled as $\mathrm{NCPCM}_{\mathrm{TiO}_{2}}, \mathrm{NCPCM}_{\mathrm{Al}_{2} \mathrm{O}_{3}}, \mathrm{NCPCM}_{\mathrm{CuO}}$ and

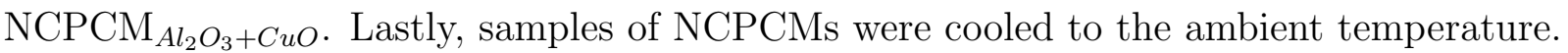

\section{Characterizations techniques}

\subsection{Microstructural and chemical interaction analysis}

An environmental scanning electron microscopy (ESEM, FEI Quanta-650) attached with the energy-dispersive $\mathrm{X}$-ray spectroscopy (EDX) system was employed to examine the surface morphology, microstructure and to visualize the surface elemental distribution of nanoparticles in NCPCMs. Fourier-transform infrared spectroscope (FTIR, Bruker Tensor27) was used to record the absorption spectra between the wave range of $400-4000 \mathrm{~cm}^{-1}$ at 


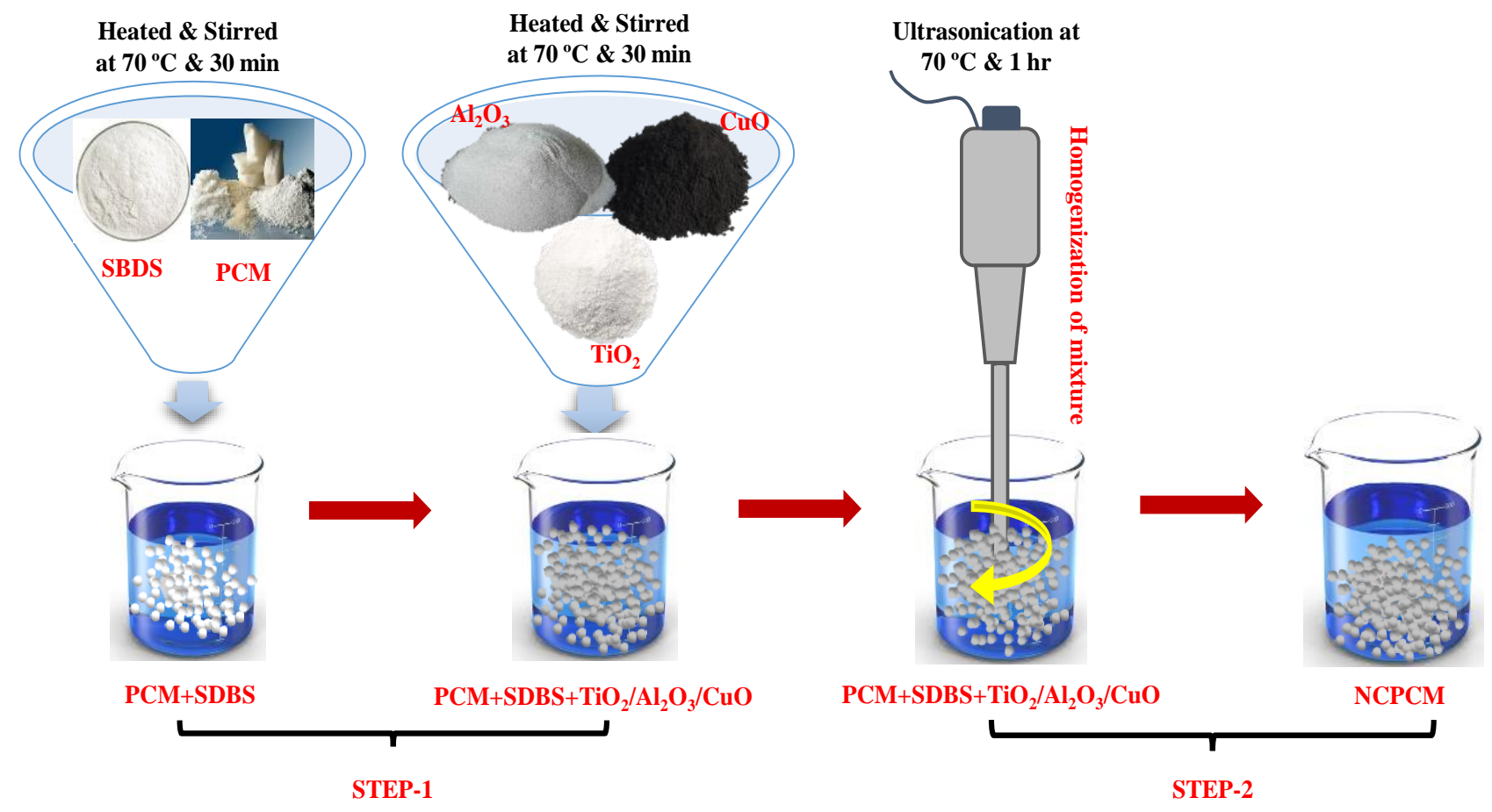

Figure 1: Schematic diagram of synthesizing of $\mathrm{TiO}_{2}, \mathrm{Al}_{2} \mathrm{O}_{3}, \mathrm{CuO}$ and $\mathrm{RT}$-35HC based mono and hybrid NCPCMs.

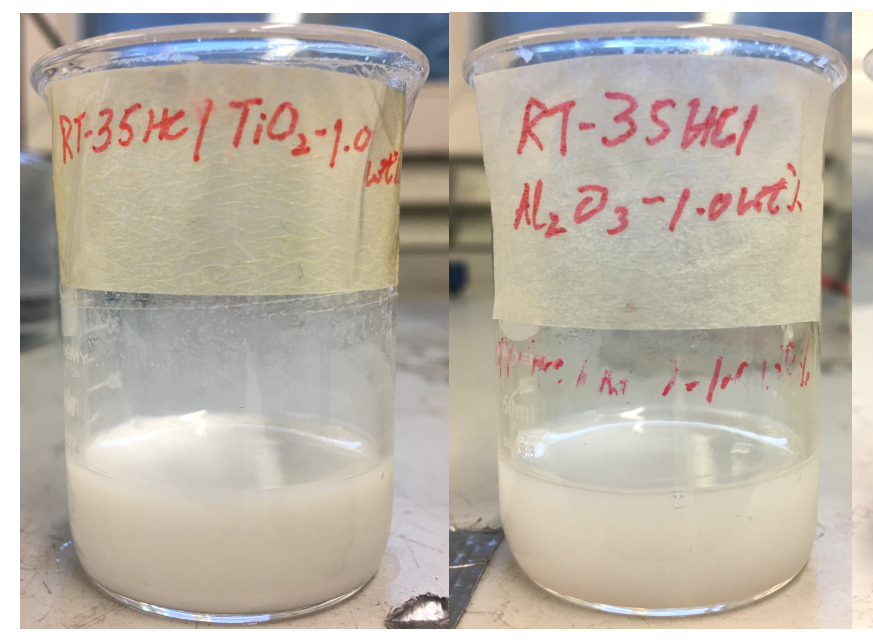

(a) (b)

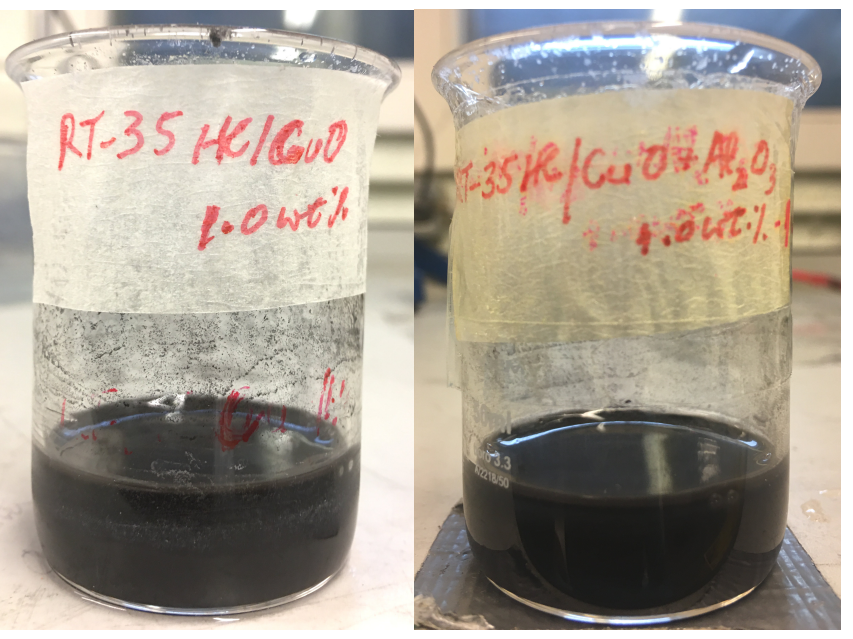

(c)

(d)

Figure 2: NCPCMs after sonication: (a) $\mathrm{NCPCM}_{\mathrm{TiO}_{2}}$, (b) $\mathrm{NCPCM}_{\mathrm{Al}_{2} \mathrm{O}_{3}}$, (c) $\mathrm{NCPCM} C \mathrm{CuO}$, (d) $\mathrm{NCPCM} \mathrm{Al}_{2} \mathrm{O}_{3}+\mathrm{CuO}$.

room temperature with the spectral resolution of $4 \mathrm{~cm}^{-1}$ and wavenumber accuracy of 0.01 $\mathrm{cm}^{-1}$ to study the chemical composition and functional groups of NCPCMs. X-ray diffractometer (XRD, Bruker D8 Advance with Da Vinci) was used to measure the XRD pattern of NCPCMs with the $2 \theta$ angle range of $5-60^{\circ}$ with a monochromatic $\mathrm{Cu}-\mathrm{K} \alpha$ radiation $(\lambda$ 
$=1.5406 \stackrel{\AA}{A}$.

\subsection{Thermophysical properties analysis}

The TGA/DSC (SDT-Q600 TA instrument Inc., UK) (error $\pm 0.1 \mu \mathrm{g}$ ) [44] was used to perform the thermogravimetric analysis (TGA) and derivative thermogravimetry (DTG) analysis of NCPCMs to measure the rate of weight loss and decomposition to address the thermal stability of NCPCMs. The aluminium pan was used filled with sample mass of $4-7 \mathrm{mg}$ and heating rate was kept at $10^{\circ} \mathrm{C} / \mathrm{min}$ for a range of $20-400^{\circ} \mathrm{C}$ under purified nitrogen purging of $100 \mathrm{~mL} / \mathrm{min}$ flow rate. Differential scanning calorimeter (DSC-2500, TA instrument Inc., UK) [45] was used to measure the phase transition thermal properties of NCPCMs. The heating and cooling rate was kept of $1{ }^{\circ} \mathrm{C} / \mathrm{min}$ for a range of $10-50^{\circ} \mathrm{C}$.

The specific heat capacity was measured of all samples using sapphire method (ASTME1269) at a heating rate of $3{ }^{\circ} \mathrm{C} / \mathrm{min}$ between temperature $10^{\circ} \mathrm{C}$ and $50^{\circ} \mathrm{C}$. The calorimeter has the accuracy of $\pm 0.04 \%$ with temperature precision of $\pm 0.005^{\circ} \mathrm{C}$. The $\mathrm{TCi}^{T M}$ thermal conductivity analyser (TCA) (C-THERM Technologies Ltd. Canada) was used to measure the thermal conductivity of RT-35HC and NCPCMs adopting a modified transient plane source (MTPS) method (ASTM-D7984) 46]. The thermal conductivity was measured as function of temperature from $20^{\circ} \mathrm{C}$ and $55^{\circ} \mathrm{C}$. For each sample, at a constant temperature, five measurements were taken and averaged was reported and maximum uncertainty in measurement was obtained of $\pm 1.0 \%$. An IR thermographic camera (FLIR-SC2600-EA2) was used to perform the infrared thermography (IRT) tests to obtain the thermal images of samples. The samples were filled immersed in a water pot and constant temperature was provided through the hot-plate.

\subsection{Thermal cooling performance analysis}

The experimental setup to perform the thermal cooling performance analysis was carried out using a passive cooling thermal management system, as shown in Figure 3. The schematic diagram shows that thermal management system consists mainly the heat sink, data acquisition system, DC power supply and the laptop. The heat sink assembly consists of plate type silicon rubber heater (OMEGALUX), K-type thermocouples (OMEGA), rubber mat for insulation, perspex sheet to visualize the physical melt fractions of RT-35HC and NCPCMs. In the experimental set up, the heat sink assembly was perfectly insulated using a rubber pad, having very low thermal conductivity. The rubber pad was placed at 
the bottom and around the heat sink with a $50 \mathrm{~mm}$ extended width/thickness of the actual dimensions of heat sink. A constant temperature was measured at the outside of the insulation during the experiment which was the same with environment room temperature. The top surface of the heat sink was covered with acrylic sheet having a thickness of $5 \mathrm{~mm}$ by keeping silicon gasket which prevent the PCM leakage, to visualize the physical melt font of molten PCM. A copper made heat sink was manufactured using computer numerical control (CNC) machine. Pure RT-35HC and NCPCMs were poured inside the heat sink. To ensure the proper stability, reduce the aggregation and uniform distribution of nanoparticles, each sample of NCPCMs was sonicated before pouring into the heat sink. A DC power supply made of Keysight Technologies (N6700C, 0.5 A/100 V) was used to provide different power levels of 3-5 W at ambient temperature, to mimic heat generation. A PC based digital data acquisition system (Agilent 34972A, USA) was used to record the temperature variation through thermocouples inserted at different points on the heat sink. The data acquisition system was connected to the laptop and Agilent Technologies, Inc. (Taft Ave. Loveland, USA) software is used to record the temperature at interval of $5 \mathrm{~s}$ during the experimentation. The uncertainty of the measured quantities is associated with the least count of the corresponding measurement devices. The uncertainty in temperature measurement according to according to ASTM standard [47] in a temperature range of $0-$ $100^{\circ} \mathrm{C}$ with maximum variation of $\pm 0.1^{\circ} \mathrm{C}$. The uncertainty in data logger is $\pm 0.1^{\circ} \mathrm{C}$. The uncertainties in voltage and current are measured of $\pm 0.01 \mathrm{~V}$ and $\pm 0.001 \mathrm{~A}$, respectively. The uncertainty in heat input are calculated using Kline and McClintock [48] technique and minimum and maximum uncertainties are obtained of $1.68 \%$ and $1.91 \%$, respectively.

\section{Results and discussions}

\subsection{ESEM and EDX analysis}

The microstructure and surface morphology of mono and hybrid NCPCMs analysed by the ESEM are presented in Figure 4. The surface microstructural features of $\mathrm{NCPCM}_{\mathrm{TiO}_{2}}$, $\mathrm{NCPCM}_{\mathrm{Al}_{2} \mathrm{O}_{3}}, \mathrm{NCPCM}_{\mathrm{CuO}}$ and $\mathrm{NCPCM}_{\mathrm{Al}_{2} \mathrm{O}_{3}+\mathrm{CuO}}$ are presented in Figure $4 \mathrm{a}, 4 \mathrm{~b}, 4 \mathrm{c}, 4 \mathrm{~d}$, $4 \mathrm{e}, 4 \mathrm{f}, 4 \mathrm{~g}$ and $4 \mathrm{~h}$ of LFD and BSED images, respectively. It can be seen from Figure 4 that the dispersion of nanoparticles in RT-35HC is uniform representing in white regions which is due to the repulsive bonding of the dispersing agent. Since the loading of nanoparticles is constant and very less despite the fact, all nanoparticles are well dispersed and 


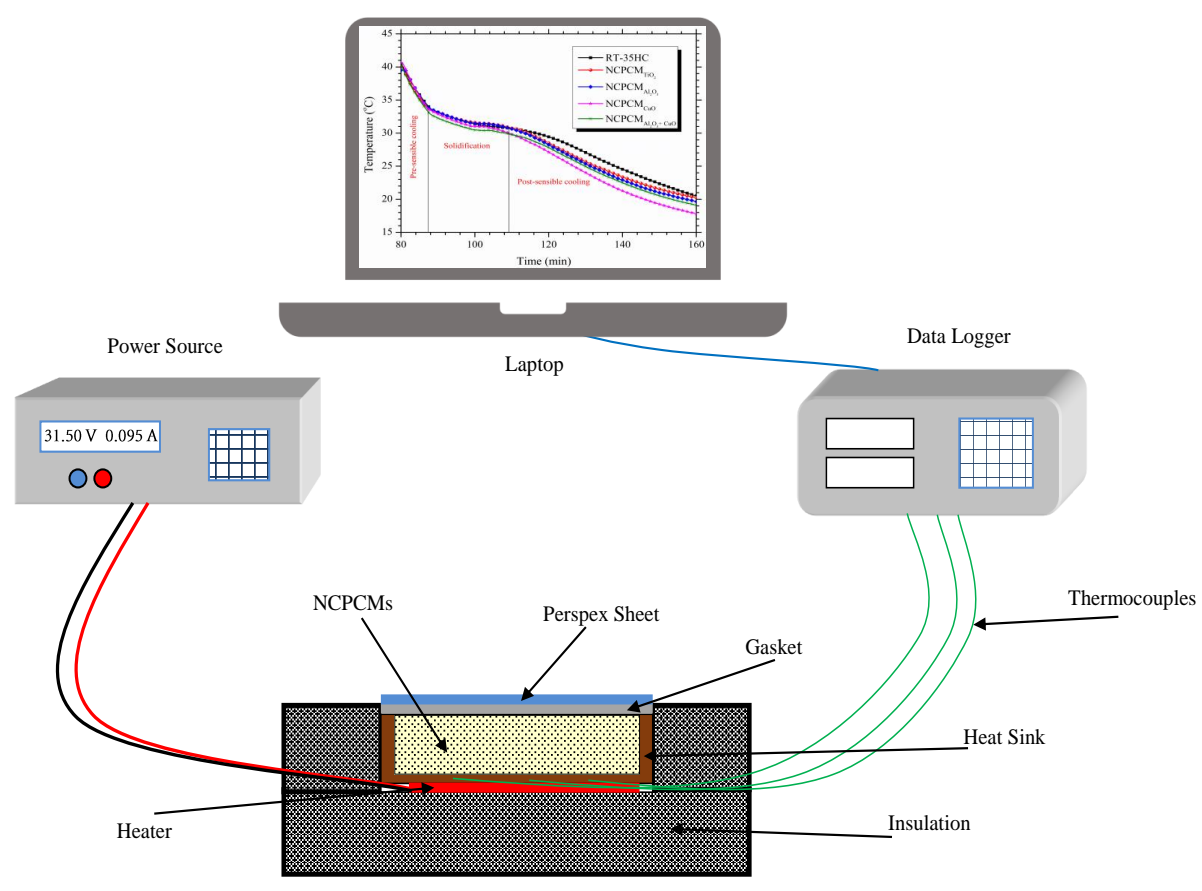

Figure 3: Schematic diagram of experimental setup.

embedded enough to show their presence in NCPCMs. Besides, the homogenous and heterogeneous percolation of nanoparticles in RT-35HC can be observed from LFD and BSED images. From Figure 4, the presence of zones characterized by the heterogeneous aggregates of nanoparticles and RT-35HC can be observed clearly. Similar observations of nanoparticles percolation in NCPCMs have been reported in Ref. 29, 30, 33. While solid-liquid phase transition of NCPCMs, the solvation, "Brownian motion" and "electrostatic repulsion" cause the nanoparticles to separate individually. However, this collision becomes more prominent between the nanoparticles by increasing the loading of the nanoparticles and Van der Waals force becomes stronger at a short range resulting in the formation of aggregates and sedimentation of nanoparticles at high concentration. Therefore, the uniform dispersion and percolation of nanoparticles depend on the size of the nanoparticles.

The EDX maps of $\mathrm{NCPCM}_{\mathrm{TiO}_{2}}$ and $\mathrm{NCPCM}_{\mathrm{Al}_{2} \mathrm{O}_{3}+\mathrm{CuO}}$ are shown in Figure 5 and 6 , respectively. Figure $5 \mathrm{a}, 5 \mathrm{~b}$ and $5 \mathrm{c}$ show the distribution of carbon $(\mathrm{C})$, oxygen $(\mathrm{O})$ and titanium (Ti) elements, respectively, present in $\mathrm{NCPCM}_{\mathrm{TiO}_{2}}$. The presence of all elements $\mathrm{C}$, $\mathrm{Ti}$ and $\mathrm{O}$ in different colours can be seen in single image of $\mathrm{TiO}_{2}$ dispersed $\mathrm{NCPCM}_{\mathrm{TiO}_{2}}$ in Figure $5 \mathrm{~d}$. The EDX mapping of carbon $(\mathrm{C})$, oxygen $(\mathrm{O})$, aluminium $(\mathrm{Al})$, and copper $(\mathrm{Cu})$ elements of hybrid $\mathrm{NCPCM}_{\mathrm{Al}_{2} \mathrm{O}_{3}+\mathrm{CuO}}$ can be seen in Figure 6a, 6b, 6c and 6d, respectively. Figure 6e

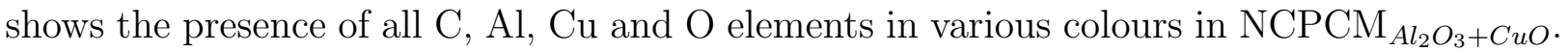


The ESEM and EDX images show the smaller zones of agglomeration of nanoparticles. The similar observations have been reported in previous studies [33, 34]. Consequently, it is recommended that for more better and uniform dispersion of the nanoparticles in PCM, the smaller size, low density and higher surface area nanoparticles are preferable [49, 50].

\subsection{FT-IR analysis}

The chemical composition and structural interaction of $\mathrm{TiO}_{2}, \mathrm{Al}_{2} \mathrm{O}_{3}$ and $\mathrm{CuO}$ dispersed NCPCMs were characterized by FT-IR spectroscopy. Figure7presents the FT-IR spectrum of nanoparticles, RT-35HC and NCPCMs and absorption peaks were observed. For instance, the three absorption peaks at $2955 \mathrm{~cm}^{-1}, 2913 \mathrm{~cm}^{-1}, 2849 \mathrm{~cm}^{-1}$ represent the medium $\mathrm{C}-\mathrm{H}$ symmetrical and anti-symmetrical stretching vibration of methyl $\left(-\mathrm{CH}_{3}\right)$ and methylene $\left(-\mathrm{CH}_{2}-\right)$ group. The peak at $1472 \mathrm{~cm}^{-1}$ identifies the medium $\mathrm{C}-\mathrm{H}$ scissoring of $-\mathrm{CH}_{2}-$ and deformation of antisymmetric stretching vibration $-\mathrm{CH}_{3}$ group in RT-35HC. The FT-IR spectrum also shows a series of absorption peaks at 1371, 1125, and $891 \mathrm{~cm}^{-1}$ which are due to the $\mathrm{C}-\mathrm{H}$ bending and scissoring vibrations. The peak at $715 \mathrm{~cm}^{-1}$ represents to the weak rocking vibration of $\mathrm{C}-\mathrm{H}$ in long-chain methyl group. The FT-IR spectrum of $\mathrm{TiO}_{2}$ shows the two peaks around 510 and $526 \mathrm{~cm}^{-1}$ which are attributed to the Ti-O stretching vibrations in $\mathrm{TiO}_{2}$. In case of $\mathrm{CuO}$, there are two stretching bands at $880 \mathrm{~cm}^{-1}$ and $1432 \mathrm{~cm}^{-1}$ which represent the characteristics bands of $\mathrm{Cu}-\mathrm{OH}$ functional group [51, 52] Furthermore, there is a small peak can be observed at $729 \mathrm{~cm}^{-1}$ which indicates the standard adsorption spectra pattern of the amorphous structure or disordered defects of $\gamma-\mathrm{Al}_{2} \mathrm{O}_{3}$. It can be revealed that both mono and hybrid NCPCMs presented the consistent peaks with that of the pure RT-35HC which means that NCPCMs contained similar characteristics of pure RT-35HC without emergence of new peak or any peak shift. This means that there no considerable chemical interaction occurred between the $\mathrm{TiO}_{2}, \mathrm{Al}_{2} \mathrm{O}_{3}$ and $\mathrm{CuO}$ and $\mathrm{RT}-$ $35 \mathrm{HC}$ and there is only physical interaction which indicate that prepared mono and hybrid NCPCMs are chemical stable.

\subsection{XRD analysis}

The crystallography analysis of $\mathrm{TiO}_{2}, \mathrm{Al}_{2} \mathrm{O}_{3}, \mathrm{CuO}, \mathrm{RT}-35 \mathrm{HC}$ and NCPCMs were identified through XRD patterns to study the crystalline phase and dimensions of unit cell, , as shown in Figure 8. The diffraction peaks of $2 \theta$ at $25.3^{\circ}(101), 37.79^{\circ}(004), 48.03^{\circ}(200)$, $53.88^{\circ}(105)$ and $55.06^{\circ}$ (211) confirm the anatase form of the $\mathrm{TiO}_{2}$ (PDF No. 03-065-5714). The peaks of $\mathrm{Al}_{2} \mathrm{O}_{3}$ confirmed the presence of $\gamma$-phase of $\mathrm{Al}_{2} \mathrm{O}_{3}$ nanoparticles at $2 \theta=19.50^{\circ}$ 
(013), $32.80^{\circ}(022), 34.60^{\circ}(117), 36.76^{\circ}(122), 39.50^{\circ}(026)$ and $45.64^{\circ}$ (220) with PDF No. 00-046-1131. The diffraction peaks at $2 \theta=32.50^{\circ}(110), 35.54^{\circ}(111), 38.70^{\circ}(111), 46.26^{\circ}$ $(112), 48.71^{\circ}(202), 53.48^{\circ}(020)$, and $58.26^{\circ}$ (202) confirmed the $\mathrm{CuO}$ (PDF No. 01-0736023). The sharp diffraction peaks of pure RT-35HC was observed at $6.85^{\circ}(002), 10.48^{\circ}$ (003), $13.91^{\circ}(004), 17.44^{\circ}(005), 19.32^{\circ}(010), 19.80^{\circ}(011), 20.83^{\circ}(012), 22.43^{\circ}(013)$, $23.32^{\circ}(105), 24.78^{\circ}(-101), 25.65^{\circ}(110), 28.12^{\circ}$ (008), $31.75^{\circ}(009), 34.75^{\circ}(-110), 35.27^{\circ}$ $(0010), 39.83^{\circ}(0-22), 42.73^{\circ}(0012), 44.60^{\circ}(207), 52.68^{\circ}(220), 53.41^{\circ}(-2-14)$ and $57.55^{\circ}$ $(-205)$ which attributed to the crystal planes of n-eicosane $\left(\mathrm{C}_{20} \mathrm{H}_{42}\right)$ with PDF No. 00-0451543. As the loading of $\mathrm{TiO}_{2}, \mathrm{Al}_{2} \mathrm{O}_{3}$ and $\mathrm{CuO}$ was kept constant of 1.0 wt.\%, a less amount of nanoparticles dispersed in pure RT-35HC. Consequently, less significant physical changes were observed in mono and hybrid NCPCMs. The XRD results revealed that the crystalline phase of RT-35HC did not alter, further both mono and hybrid NCPCMs samples contain the peaks of $\mathrm{TiO}_{2}, \mathrm{Al}_{2} \mathrm{O}_{3}$ and $\mathrm{CuO}$.

\subsection{TGA and DTG analysis}

Figure 9 presents the thermal gravimetric analysis of RT-35HC and hybrid NCPCMs to investigate their thermal stability. The thermal stability of NCPCMs is estimated on the onset temperature of PCM degradation and rate of weight loss at which is occurs. The TGA and DTG curves show the one-step and two-step thermal degradation process, respectively. The TGA curves of RT-35HC and NCPCMs, shown in Figure 9a, represent that there is no distinguishable weight loss in any sample up to $\sim 120^{\circ} \mathrm{C}$. The rate of weight loss increases with the increase of temperature and reaches at the maximum degradation temperature with constant residual. For RT-35HC, the initial disintegration starts at $217.70^{\circ} \mathrm{C}$ and maximum degradation temperature is $255.01^{\circ} \mathrm{C}$ with $1.85 \%$ charred residue. While decomposition process, caused by the evaporation of pure RT-35HC, the hydrocarbon chains breakdown into monomers $\left(\mathrm{CH}_{3} \mathrm{CH}: \mathrm{CH}+\mathrm{CH}_{4}\right)$. The onset decomposition and maximum degradation temperatures of all samples are summarized in Table 2 and in case of hybrid $\mathrm{NCPCM}_{\mathrm{Al}_{2} \mathrm{O}_{3}+\mathrm{CuO}}$, the charred reside was $3.62 \%$ at $262.78^{\circ} \mathrm{C}$ and remained constant subsequently. In NCPCMs, the nanoparticles create the protective layer on the surface of RT-35HC which delays the vaporization of RT-35HC during the thermal degradation. The DTG curves of RT-35HC and NCPCMs are shown in Figure $9 \mathrm{~b}$ and revealed that addition of nanoparticles have improved the thermal stability, because no decompositions was observed in samples until $\sim 150^{\circ} \mathrm{C}$. Thus, hybrid $\mathrm{NCPCM}_{\mathrm{Al}_{2} \mathrm{O}_{3}+\mathrm{CuO}}$ can effectively be used for thermal management 
systems. The improvement in thermal stability can be explained by the following reasons: (i) the onset decomposition temperature is related to the specific heat capacity of NCPCMs which can be raised by the specific heat capacity of nanoparticles and (ii) enhanced thermal conductivity of NCPCMs which can transfer heat faster and uniformly within the PCM [53].

Table 2: The temperature changes and residue of $\mathrm{TiO}_{2}, \mathrm{Al}_{2} \mathrm{O}_{3}, \mathrm{CuO}$ and $\mathrm{RT}-35 \mathrm{HC}$ based mono and hybrid NCPCMs.

\begin{tabular}{|c|c|c|c|}
\hline Sample & Onset decomposition temperature $\left({ }^{\circ} \mathrm{C}\right)$ & Maximum-rate degradation temperature $\left({ }^{\circ} \mathrm{C}\right)$ & Residue $(\%)$ \\
\hline RT- $35 \mathrm{HC}$ & 217.70 & 255.01 & 1.85 \\
\hline $\mathrm{NCPCM}_{\mathrm{TiO}_{2}}$ & 226.77 & 263.55 & 1.96 \\
\hline $\mathrm{NCPCM}_{\mathrm{Al}_{2} \mathrm{O}_{3}}$ & 225.24 & 264.07 & 4.01 \\
\hline $\mathrm{NCPCM}_{\mathrm{CuO}}$ & 228.37 & 264.57 & 6.04 \\
\hline $\mathrm{NCPCM}_{\mathrm{Al} l_{2} \mathrm{O}_{3}+\mathrm{CuO}}$ & 224.87 & 262.78 & 3.62 \\
\hline
\end{tabular}

\subsection{DSC analysis}

DSC analysis presents the phase-transition temperatures and latent-heat of melting/solidification of NCPCMs, as shown in Figure 10. Figure 10a and 10b present the endothermic and exothermic curves, respectively, of RT-35HC and NCPCMs and measured values of phasetransition thermal properties are summarized in Table 3. It can be seen that the addition of nanoparticles have slightly changed the thermal properties of RT-35HC after synthesizing. The latent-heat of melting/solidification of NCPMCs were decreased with the addition of nanoparticles, as expected. A single endothermic peak is observed of RT-35HC and NCPCMs during melting, indicating an isomorphous crystalline form of RT-35HC either in a pristine state or in the NCPCMs one. Contrary, a bimodal crystallization behaviour is predicted of RT-35HC and NCPCMs by presenting a main exothermic peak temperature along with an additional peak of higher temperature during solidification process. This twophase transitions phenomenon is ascribed by the appearance of a metastable rotator phase prior to completing the complete crystallization as a results of the heterogeneous nucleation during the cooling process [8, 54, 55].

The comparison of the melting $\left(\Delta H_{m}\right)$ and solidification $\left(\Delta H_{s}\right)$ enthalpies of RT-35HC and NCPCMs are presented in Figure 10c. The $\Delta H_{m}$ and $\Delta H_{s}$ of RT-35HC are determined of 255.88 and $260.06 \mathrm{~J} / \mathrm{g}$, respectively. The reduction in $\Delta H_{m}$ of $\mathrm{NCPCM}_{\mathrm{TiO}_{2}}, \mathrm{NCPCM}_{\mathrm{Al}_{2} \mathrm{O}_{3}}$, $\mathrm{NCPCM}_{C u O}$ and $\mathrm{NCPCM}_{\mathrm{Al}_{2} \mathrm{O}_{3}+\mathrm{CuO}}$ has been obtained of $7.83 \%, 8.24 \%, 8.59 \%$ and $10.72 \%$ as compared to the pure RT-35HC. Similarly, the maximum reduction in $\Delta H_{s}$ latent-heats are $7.98 \%, 7.08 \%, 9.47 \%$, and $11.81 \%$ for $\mathrm{NCPCM}_{\mathrm{TiO}_{2}}, \mathrm{NCPCM}_{\mathrm{Al}_{2} \mathrm{O}_{3}}, \mathrm{NCPCM}_{\mathrm{CuO}}$ and

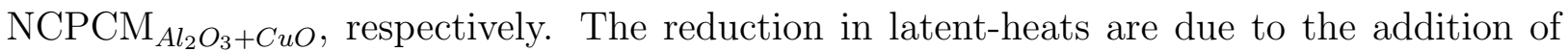


nanoparticles and mass fraction $(\omega)$ of crystallized RT-35HC in NCPCMs is determined by the Equation 1:

$$
\omega=\frac{\Delta H_{N C P C M}}{\Delta H_{P C M}} \times 100
$$

where, $\triangle H_{N C P C M}$ and $\triangle H_{P C M}$ are the endothermic latent-heat of NCPCM and pure PCM, respectively. While synthesising of NCPCMs, the nanoparticles replace the RT$35 \mathrm{HC}$ molecules resulting in reduce the latent-heat capacity of the NCPCMs which lead to the absorption/release of more energy. The degree of super-cooling $(\Delta T)$ of NCPCMs is presented in Figure $10 \mathrm{~d}$. The peak melting temperature $\left(\mathrm{T}_{m}\right)$ and crystallization temperature $\left(\mathrm{T}_{c}\right)$ of RT-35HC are determined as $36.09^{\circ} \mathrm{C}$ and $31.71^{\circ} \mathrm{C}$, respectively. The maximum deviations in $\mathrm{T}_{m}$ are determined as $-0.30 \%,-1.14 \%,-0.97 \%$ and $-0.08 \%$ for $\mathrm{NCPCM}_{\mathrm{TiO}_{2}}$, $\mathrm{NCPCM}_{\mathrm{Al}_{2} \mathrm{O}_{3}}, \mathrm{NCPCM}_{\mathrm{CuO}}$ and $\mathrm{NCPCM}_{\mathrm{Al}_{2} \mathrm{O}_{3}+\mathrm{CuO}}$, respectively, compared to the RT-35HC. The slight variations are observed in $\mathrm{T}_{c}$ which are due the crystallization confinement of the nanoparticles surface layers within the NCPCMs. This interfacial surface layers cause to form the imperfect $\mathrm{RT}-35 \mathrm{HC}$ resulting in a slight variation in $\mathrm{T}_{m}$. These two factors result in an increase in $\Delta T$. The reduction in $\Delta T$ for $\mathrm{NCPCM}_{A l_{2} \mathrm{O}_{3}+C u O}$ is obtained of $4.32^{\circ} \mathrm{C}$, which shows the better significance hybrid nanoparticles as nucleating agents compared to the mono nanoparticles in terms of its surface adsorption and effective homogeneous nucleation.

Figure $10 \mathrm{e}$ illustrates the experimental and calculated latent-heat of fusion for NCPCMs, calculated using Equation 2 [56]

$$
\Delta L_{N C P C M}=\Delta L_{P C M} \cdot \omega=\Delta L_{P C M}(1-\varphi)
$$

where $\triangle L_{N C P C M}$ and $\triangle L_{P C M}$ calculated and experimental latent-heat of fusion of NCPCM and PCM, respectively, $\omega$ and $\varphi$ are the mass fraction of PCM and nanoparticles, respectively. It can be revealed that experimental values of latent-heat of fusion of mono and hybrid NCPCMs are lower than the calculated values. The deviation in results is due the type of the nanoparticles, since the loading of all nanoparticles in NCPCMs is constant. The relative error (RE) of experimental and calculated values has been obtained $6 \sim 9 \%$ for all NCPCMs, given in Table 3. The similar trend of deviations in experimental and calculated values latent-heat of fusion have reported in Refs. [36, 8, 56. The results reveal

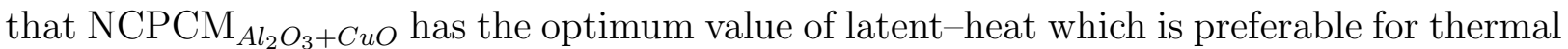


management systems. The discrepancies in latent-heat values are because of the surface 327 morphology, structure, size and rate of dispersion of the nanoparticles while synthesising 328 the NCPCMs. 


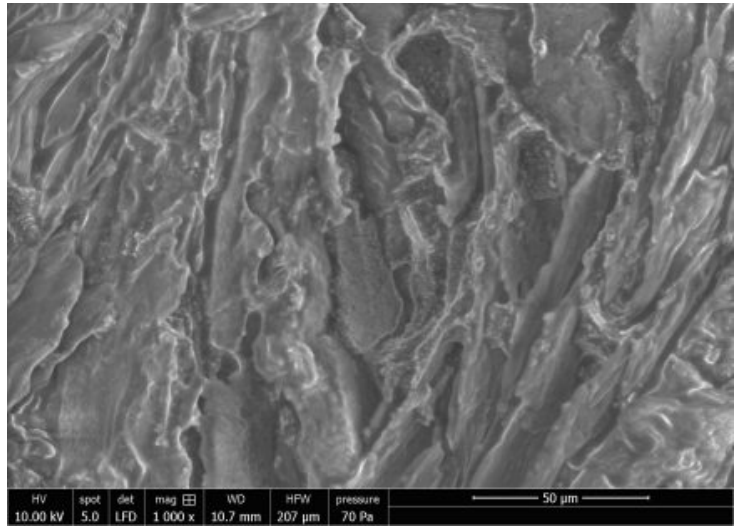

(a)

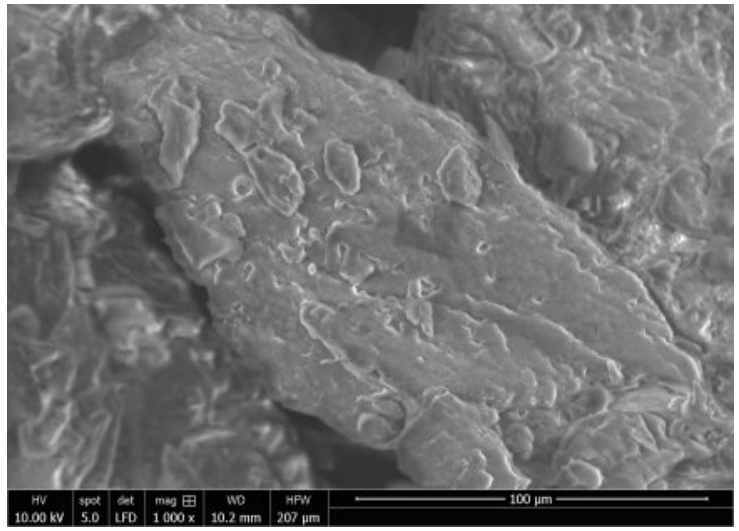

(c)

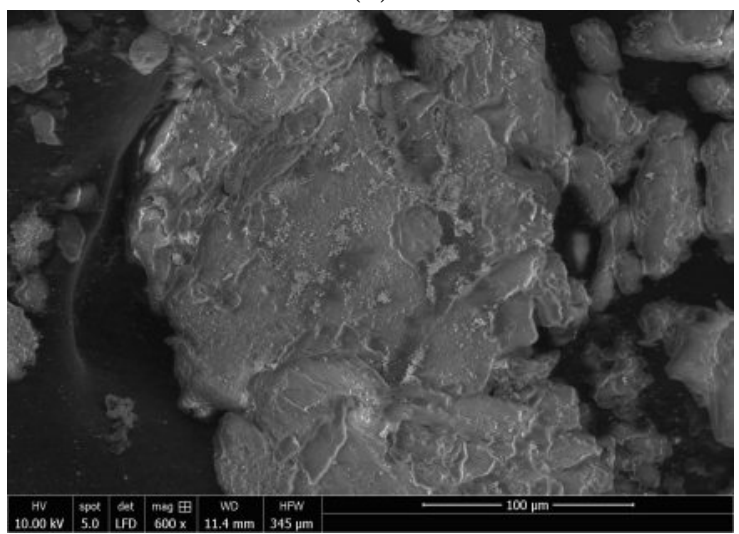

(e)

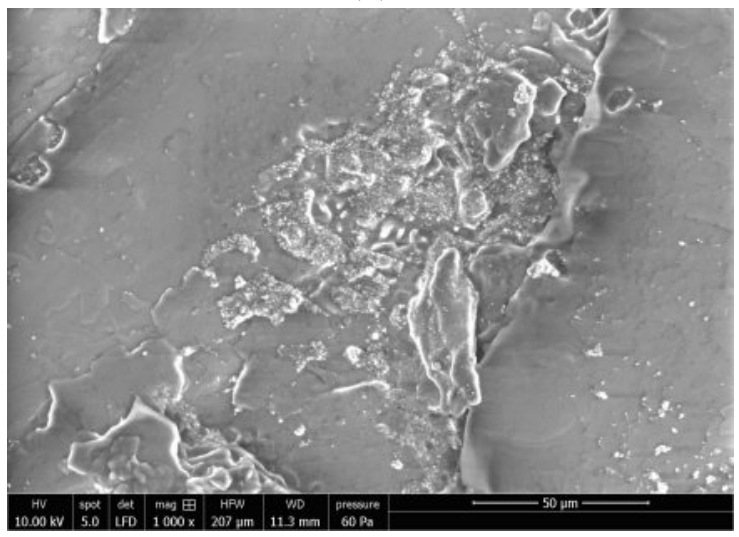

(g)

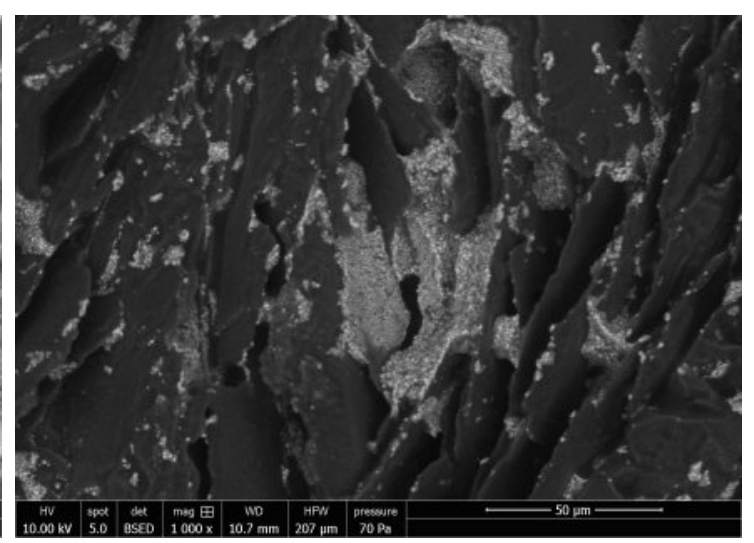

(b)

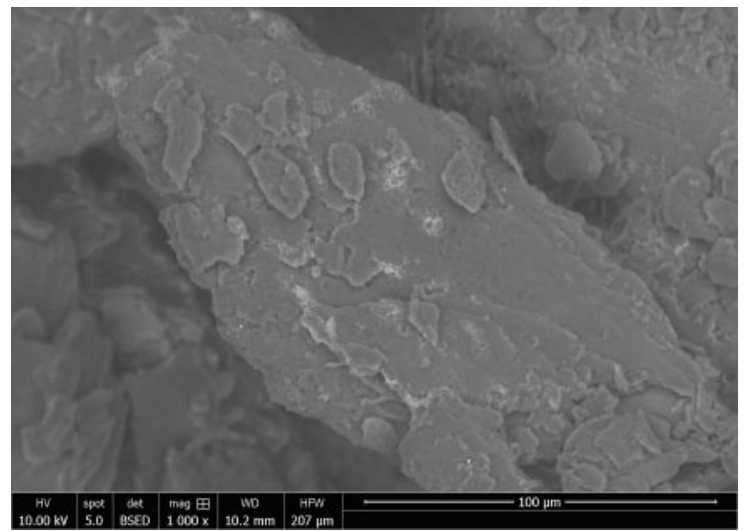

(d)

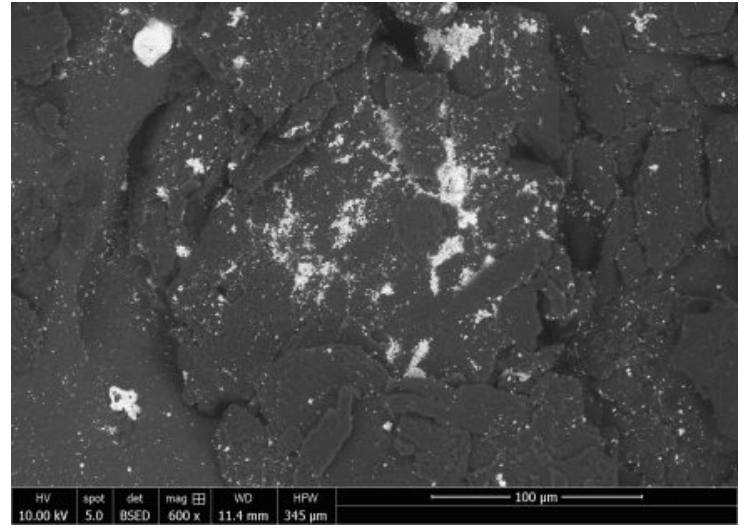

(f)

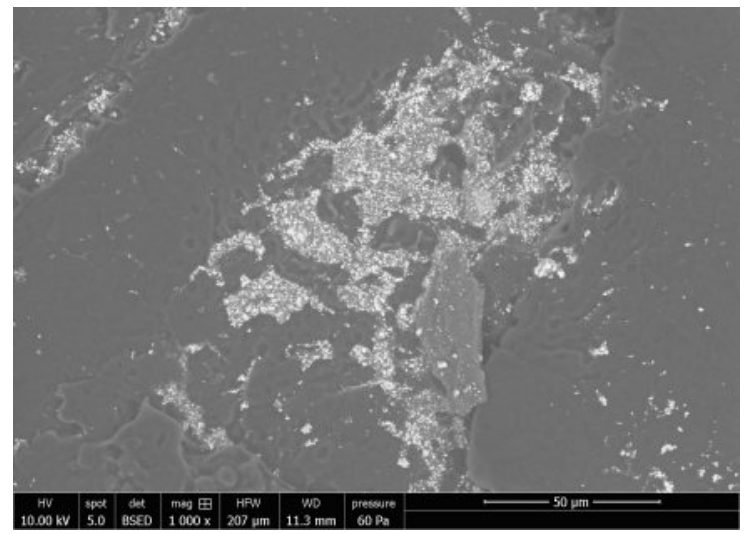

(h)

Figure 4: ESEM images of $\mathrm{NCPCM}_{\mathrm{TiO}_{2}}$ (a) LFD and (b) $\mathrm{BSED}, \mathrm{NCPCM}_{\mathrm{Al}_{2} \mathrm{O}_{3}}$ (c) $L F D$ and (d) BSED, NCPCM $C u O$ (e) LFD and (f) BSED, and $N C P C M_{\mathrm{Al}_{2} \mathrm{O}_{3}+\mathrm{CuO}}$ (g) $L F D$ and (h) $B S E D$. 


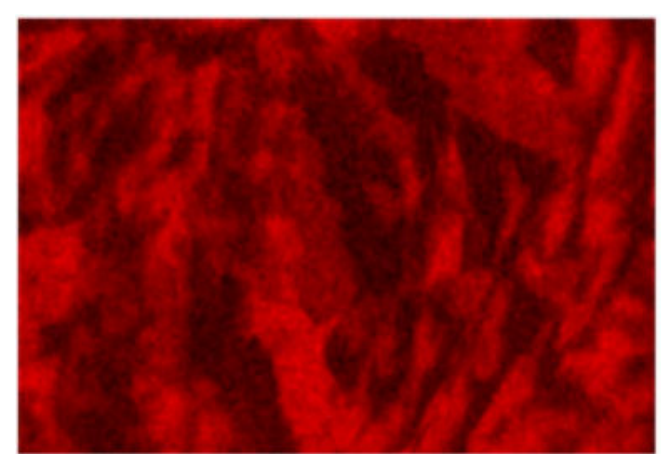

5

(a)

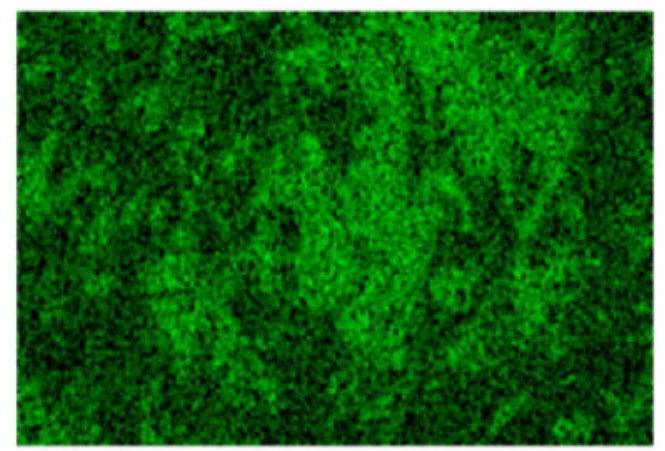

$50 \mu \mathrm{m}$

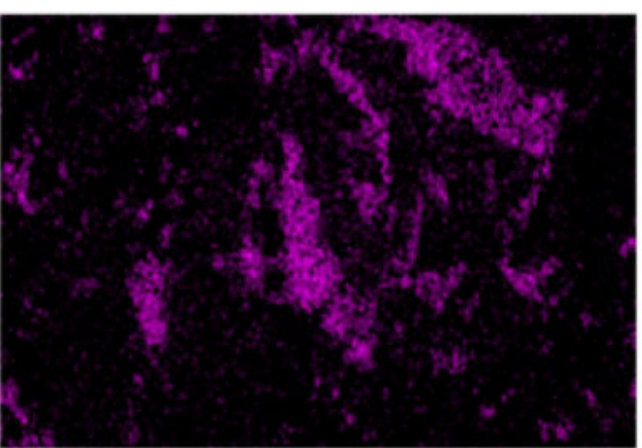

$50 \mu \mathrm{m}$

(b)

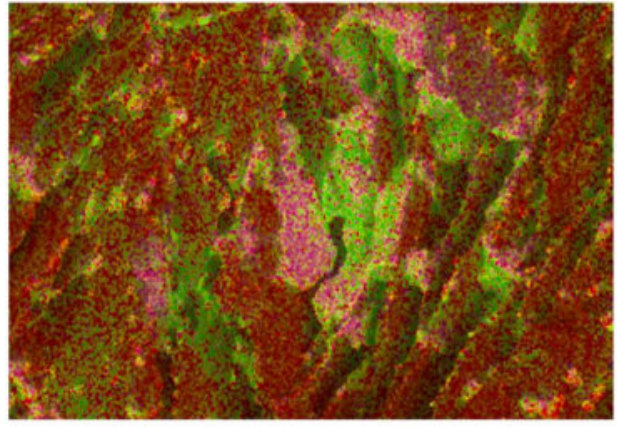

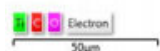

(d)

Figure 5: EDX mapping of $\mathrm{NCPCM}_{\mathrm{TiO}_{2}}$ (a) carbon-(red), (b)-oxygen-(purple), (c) Titanium-(green), (d)-EDX map of oxygen, carbon, and titanium elements present in $\mathrm{NCPCM}_{\mathrm{TiO}_{2}}$. 


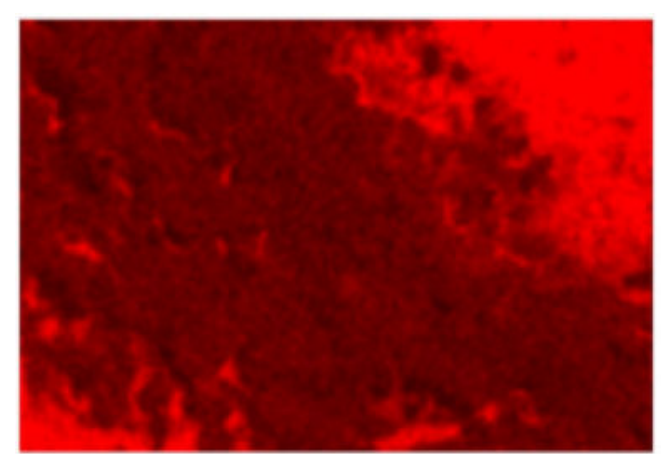

$\sqrt{50 \mu \mathrm{m}}$

(a)

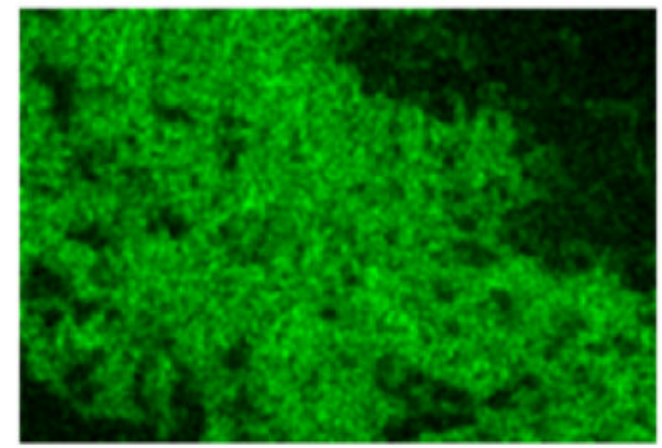

$\longdiv { 5 0 \mu \mathrm { m } }$

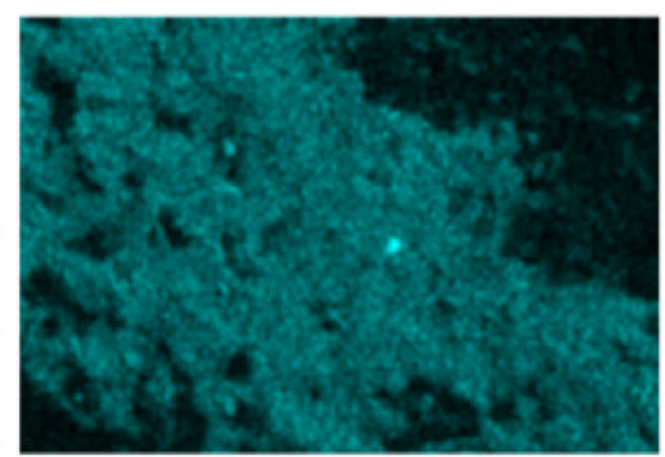

$\longdiv { 5 0 \mu \mathrm { m } }$

(b)

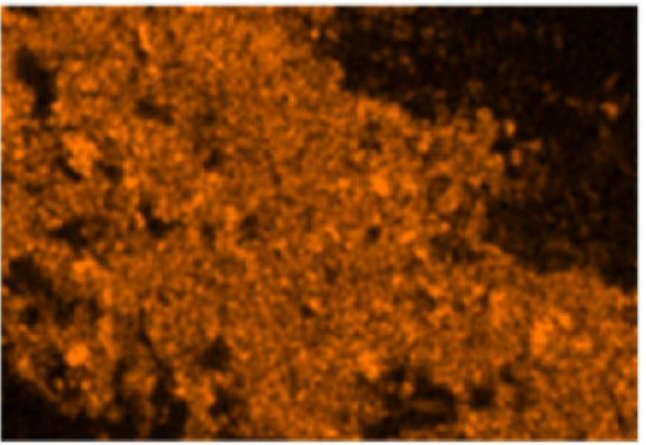

$\longdiv { 5 0 \mu \mathrm { m } }$

(c)

(d)

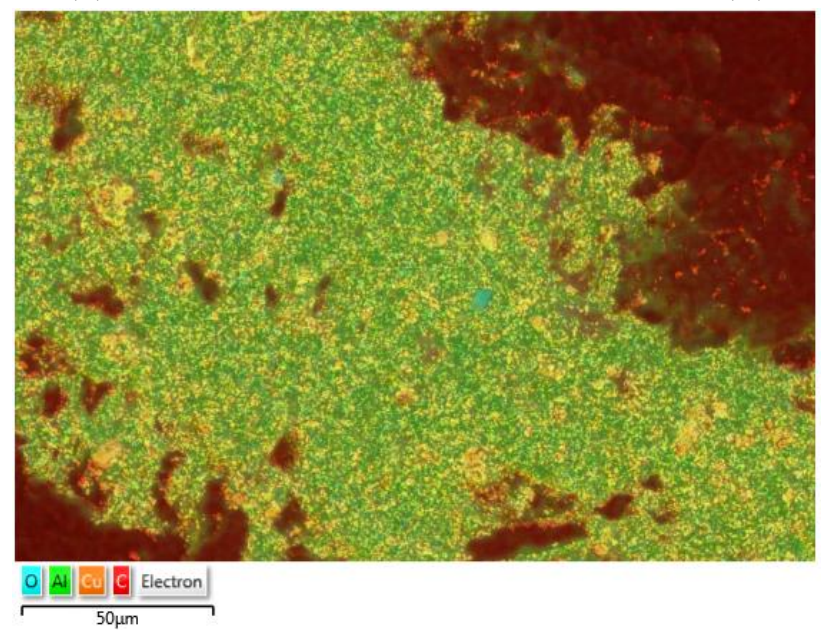

(e)

Figure 6: EDX mapping of $\mathrm{NCPCM}_{\mathrm{Al}_{2} \mathrm{O}_{3}+\mathrm{CuO}}$ (a) carbon-(red), (b)-oxygen-(cyan), (c) Titanium-(green). 


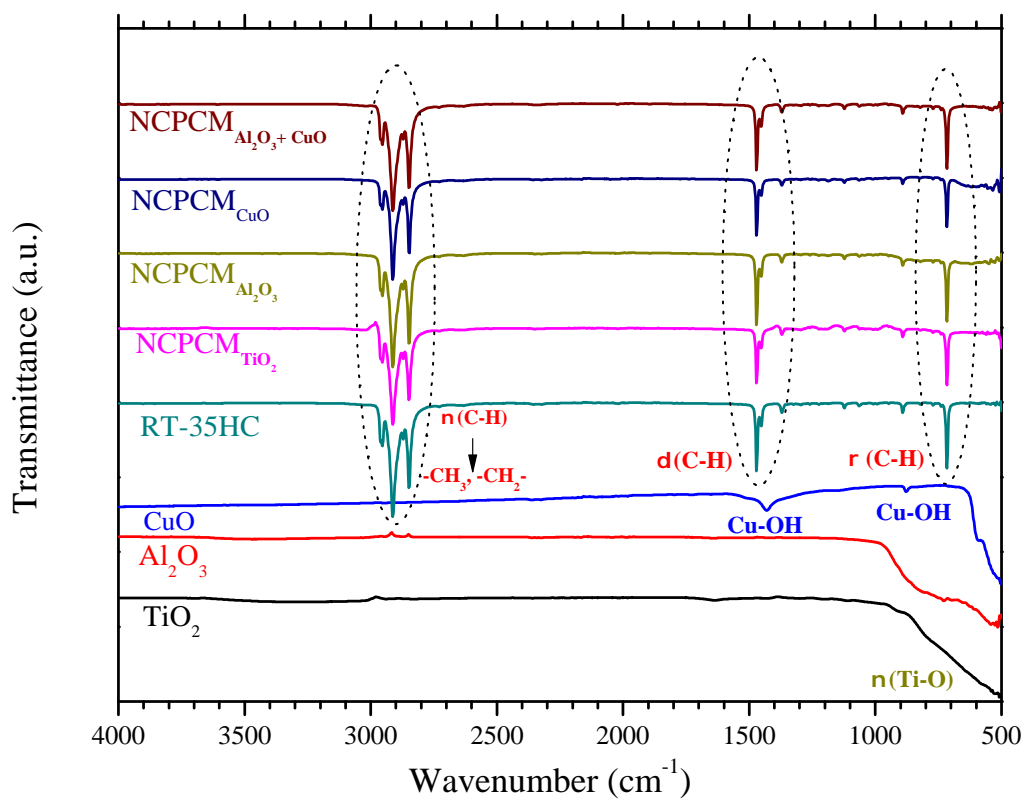

Figure 7: FT-IR spectrum of $\mathrm{TiO}_{2}, \mathrm{Al}_{2} \mathrm{O}_{3}, \mathrm{CuO}$ and $\mathrm{RT}-35 \mathrm{HC}$ based mono and hybrid NCPCMs.

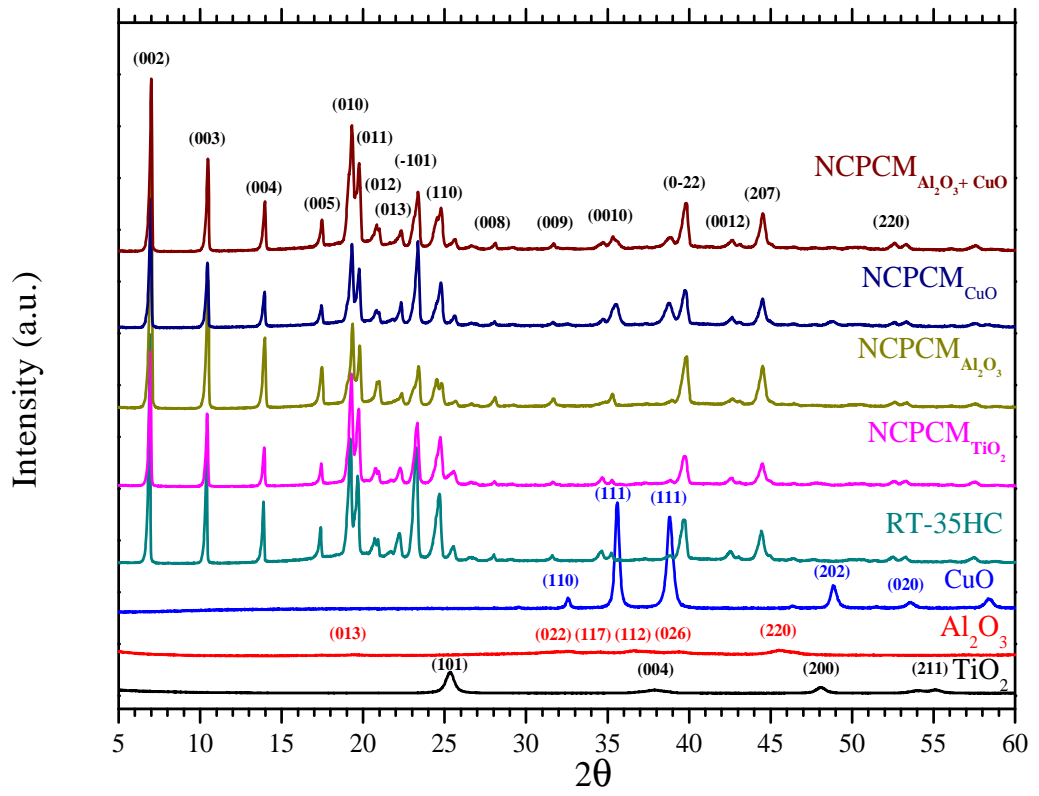

Figure 8: XRD pattern of $\mathrm{TiO}_{2}, \mathrm{Al}_{2} \mathrm{O}_{3}, \mathrm{CuO}$ and $\mathrm{RT}-35 \mathrm{HC}$ based mono and hybrid NCPCMs. 


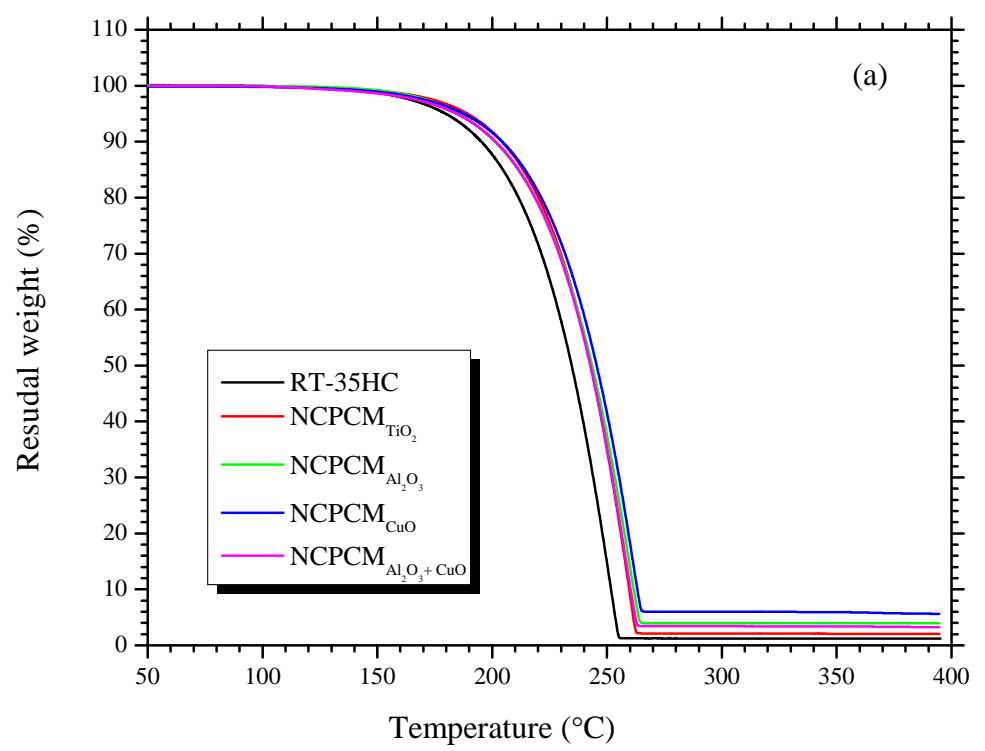

(a)

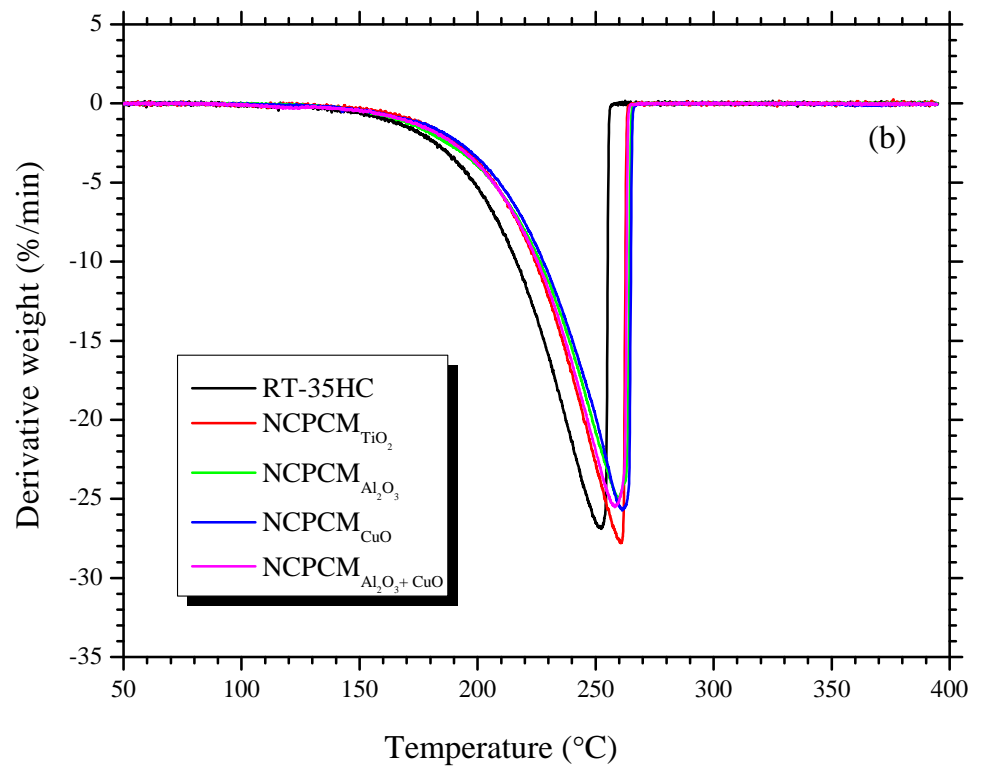

(b)

Figure 9: (a)-TGA and (b)-DTG thermograms of $\mathrm{TiO}_{2}, \mathrm{Al}_{2} \mathrm{O}_{3}, \mathrm{CuO}$ and $\mathrm{RT}-35 \mathrm{HC}$ based mono and hybrid NCPCMs. 


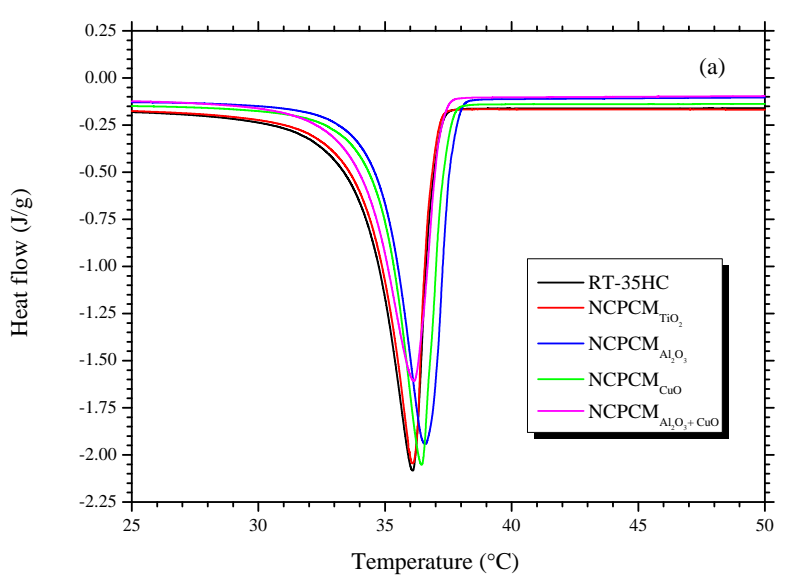

(a)

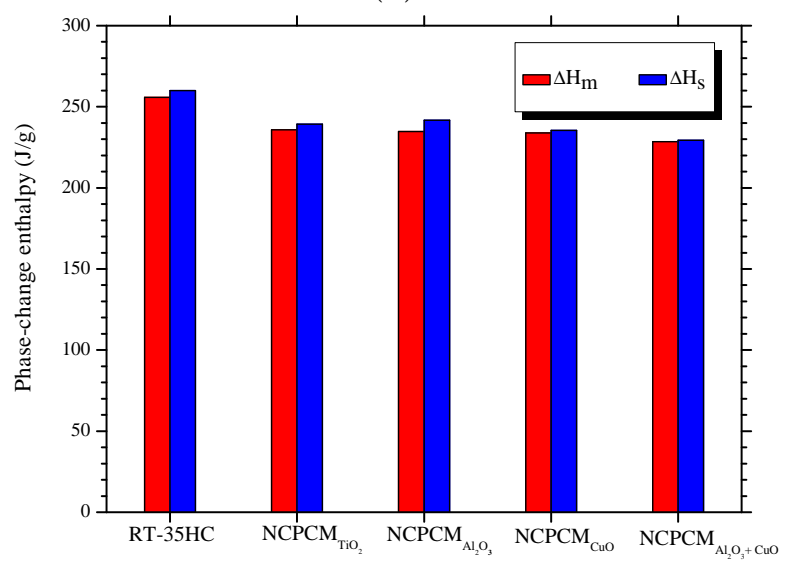

(c)

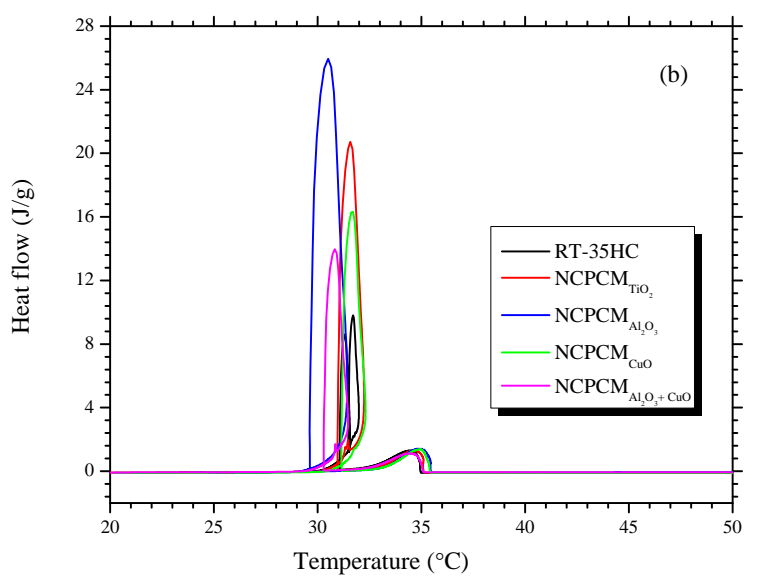

(b)

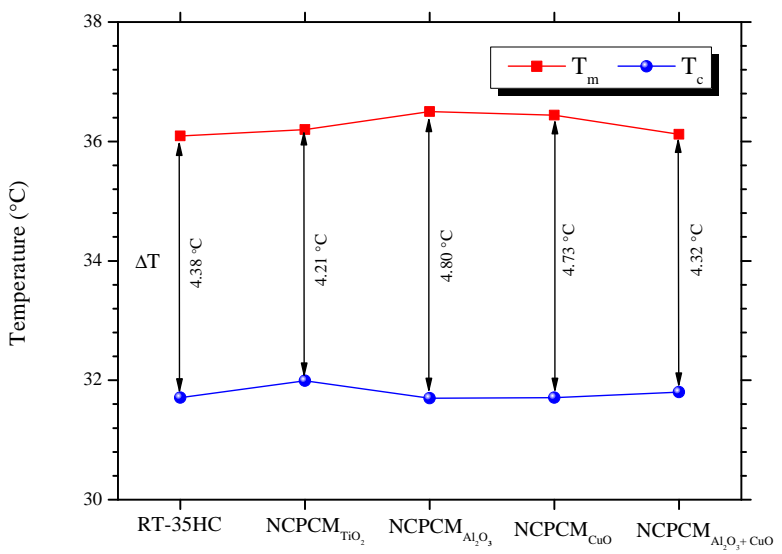

(d)

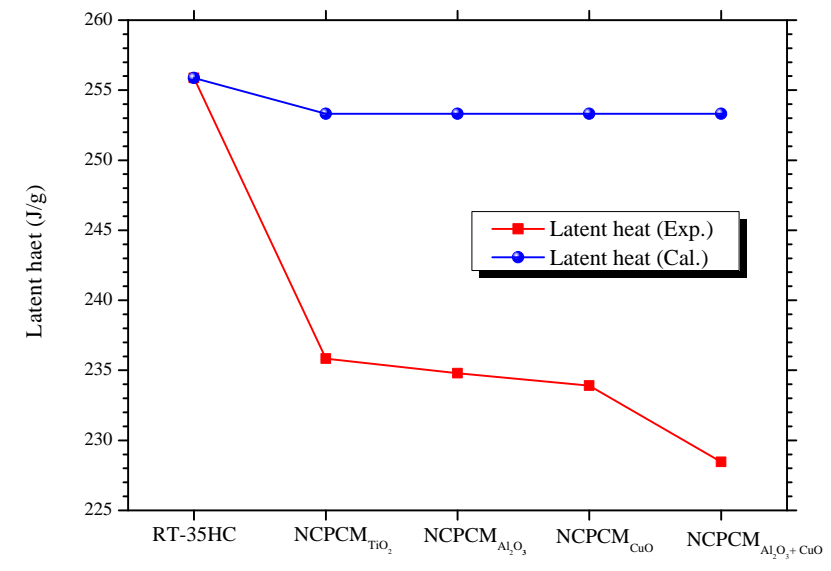

(e)

Figure 10: The results of (a) Melting, (b) Solidification curves, (c) Phase-change enthalpies, (d) Degree of super-cooling and (e) Comparison of latent-heats of fusions of $\mathrm{TiO}_{2}, \mathrm{Al}_{2} \mathrm{O}_{3}$, $\mathrm{CuO}$ and $\mathrm{RT}-35 \mathrm{HC}$ based mono and hybrid NCPCMs. 


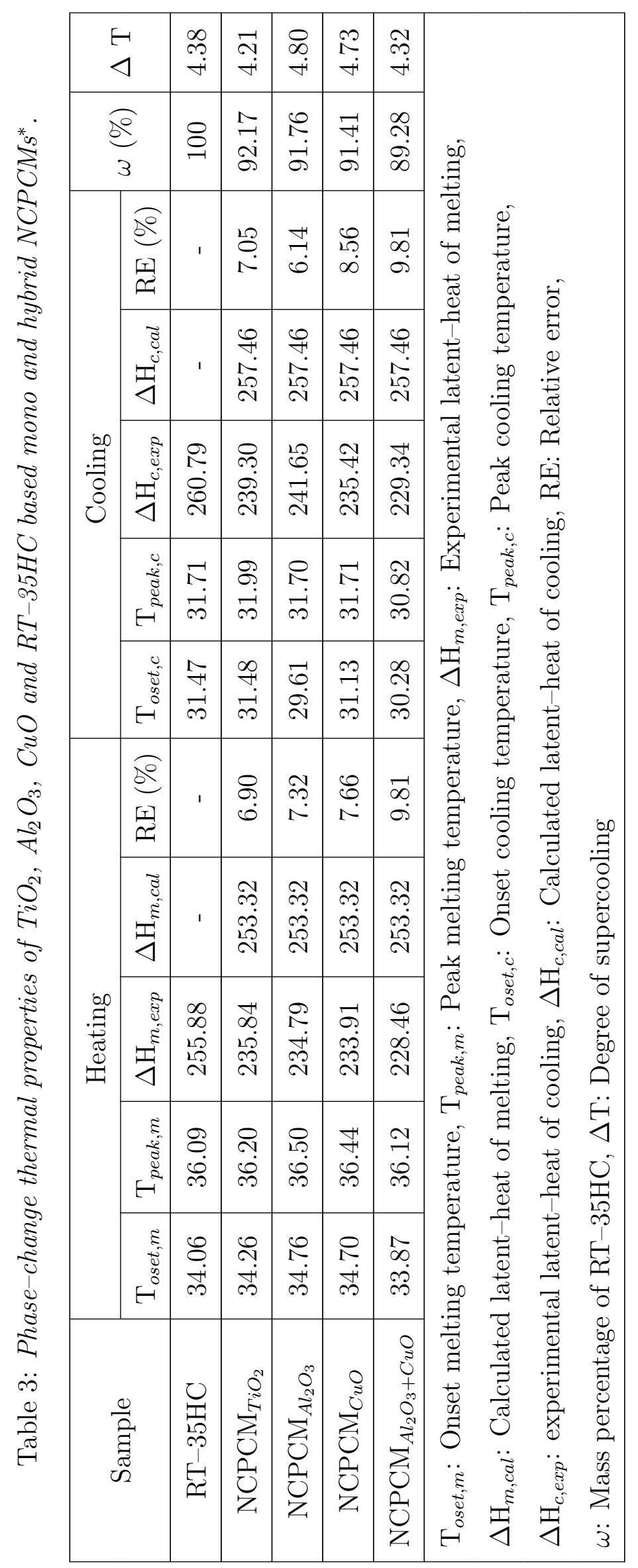




\subsection{Thermal conductivity measurements}

Figure 11 presents the results of thermal conductivity $(k)$ and thermal conductivity enhancement factor $(\eta)$ of RT-35HC and NCPCMs. It can be seen that by dispersing the nanoparticles thermal conductivity generally increases because of the higher thermal conductivity of nanoparticles. The average thermal conductivity of RT-35HC and NCPCMs is measured for solid-phase $\left(20-30^{\circ} \mathrm{C}\right)$, phase-change $\left(\sim 35^{\circ} \mathrm{C}\right)$ and liquid-phase $\left(40-55^{\circ} \mathrm{C}\right)$ regions with an increment of $5^{\circ} \mathrm{C}$. It can be evidenced that the constant trend is predicted in enhancement in thermal conductivity in solid and liquid phases. However, a sharp increasing and decreasing behaviour was predicted when the temperature increased from $30^{\circ} \mathrm{C}$ to $35^{\circ} \mathrm{C}$ and $35^{\circ} \mathrm{C}$ to $40^{\circ} \mathrm{C}$, respectively. This behaviour reveals that thermal conductivity is strongly depended on the temperature. The phenomenon of sudden increase and decrease in thermal conductivity was due to the random motion of molecules within a disordered microstructure of lattice in liquid-phase. The maximum thermal conductivities of $0.340,0.464$, $0.461,0.469$ and $0.472 \mathrm{~W} / \mathrm{m} . \mathrm{K}$ were obtained at phase-change temperature $\left(\sim 35^{\circ} \mathrm{C}\right)$ for $\mathrm{RT}-35 \mathrm{HC}, \mathrm{NCPCM}_{\mathrm{TiO}_{2}}, \mathrm{NCPCM}_{\mathrm{Al}_{2} \mathrm{O}_{3}}, \mathrm{NCPCM}_{\mathrm{CuO}}$ and $\mathrm{NCPCM}_{\mathrm{Al}_{2} \mathrm{O}_{3}+\mathrm{CuO}}$, respectively, shown in Figure 11a. However, the maximum thermal conductivities for solid phase at $20^{\circ} \mathrm{C}$ were obtained of $0.214,0.320,0.282,0.331$ and $0.328 \mathrm{~W} / \mathrm{m} . \mathrm{K}$ for RT-35HC, $\mathrm{NCPCM}_{\mathrm{TiO}_{2}}$, $\mathrm{NCPCM}_{\mathrm{Al}_{2} \mathrm{O}_{3}}, \mathrm{NCPCM}_{\mathrm{CuO}}$ and $\mathrm{NCPCM}_{\mathrm{Al}_{2} \mathrm{O}_{3}+\mathrm{CuO}}$, respectively. The higher thermal conductivities at phase-change temperature $\left(\sim 35^{\circ} \mathrm{C}\right)$ is because of the phase-change temperature range $34-36^{\circ} \mathrm{C}$ at which the $\mathrm{NCPCM}$ is in metastable condition. At phase-change temperature, the crystalline structure of RT-35HC becomes unstable and the increase in temperature accelerates the molecular vibration of in the lattice, thus thermal conductivity of RT-35HC and NCPCMs increases dramatically at the melting point $\left(\sim 35^{\circ} \mathrm{C}\right)$ [57]. It

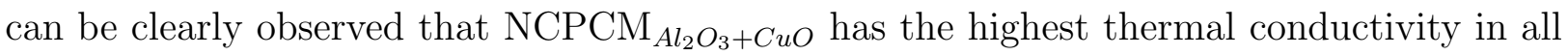
three phases. Furthermore, the percentage of $\eta$ of RT-35HC and NCPCMs is shown in Figure 11b, as given by Equation 3 :

$$
\eta=\frac{k_{N C P C M}-k_{P C M}}{k_{P C M}} \times 100
$$

where, $k_{N C P C M}$ and $k_{P C M}$ are the thermal a conductivity of NCPCM and pure PCM, respectively.

Figure $11 \mathrm{~b}$ presents an increasing trend in enhancement thermal conductivity are observed with change of temperature. A relative enhancements of $55.0 \%, 54.0 \%$ and $53.7 \%$ 


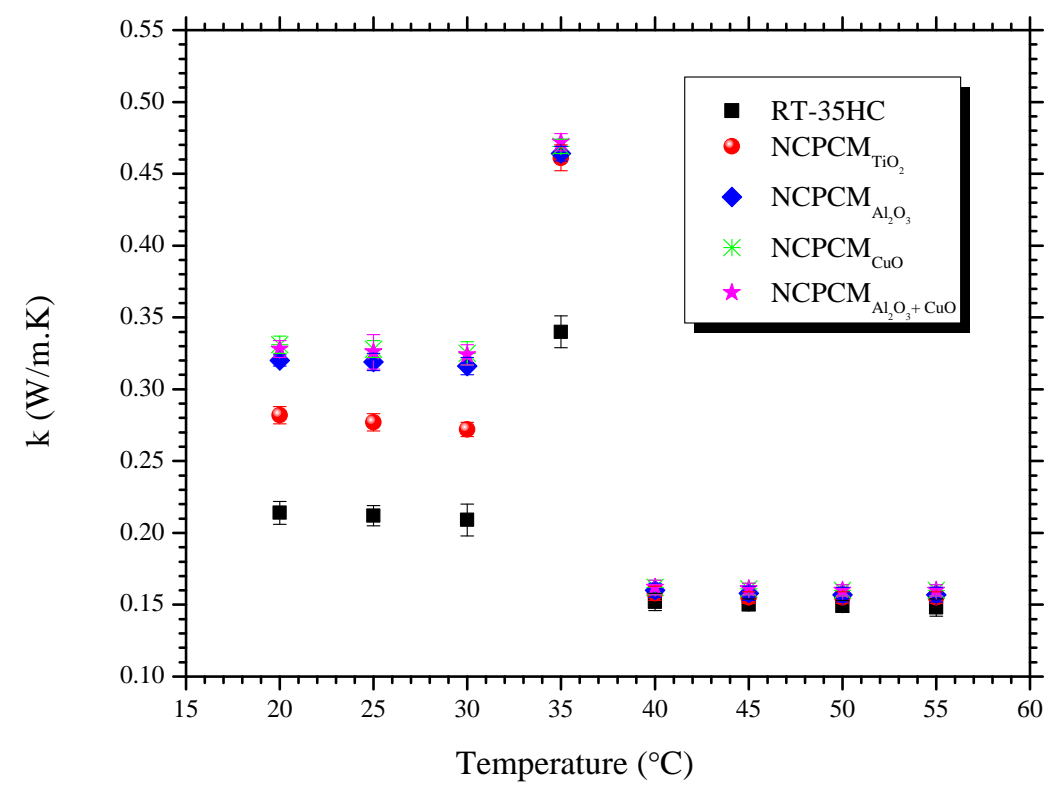

(a)

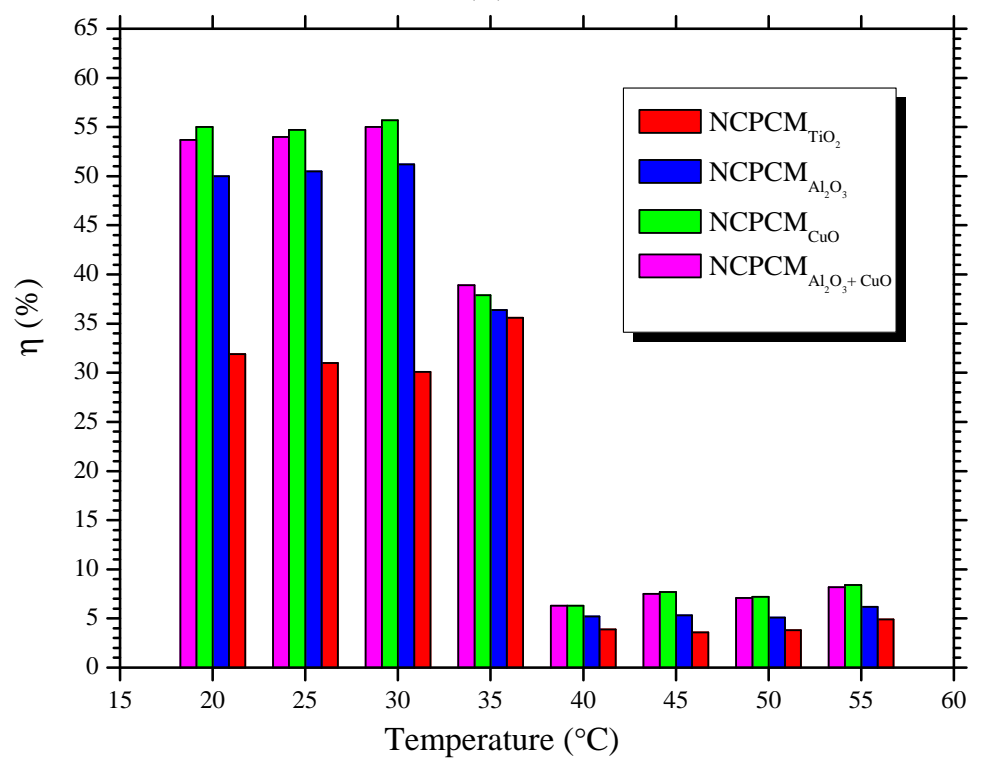

(b)

Figure 11: The results of (a) thermal conductivity and (b) thermal conductivity enhancement factor of $\mathrm{TiO}_{2}, \mathrm{Al}_{2} \mathrm{O}_{3}, \mathrm{CuO}$ and $\mathrm{RT}-35 \mathrm{HC}$ based mono and hybrid NCPCMs as a function of temperature.

are obtained for $\mathrm{NCPCM}_{\mathrm{Al}_{2} \mathrm{O}_{3}+\mathrm{CuO}}$ at $30^{\circ} \mathrm{C}, 25^{\circ} \mathrm{C}$ and $20^{\circ} \mathrm{C}$, respectively, compared to the RT-35HC. However, higher percentage enhancement in thermal conductivity is observed for $\mathrm{NCPCM}_{\mathrm{CuO}}$ of $55.7 \%, 54.7 \%$ and $55.0 \%$ at $30^{\circ} \mathrm{C}, 25^{\circ} \mathrm{C}$ and $20^{\circ} \mathrm{C}$, respectively, compared to the RT-35HC. The higher enhancement in thermal conductivity in case of $\mathrm{CuO}$ nanoparticles is because of higher thermal conductivity of $\mathrm{CuO}$ nanoparticles compared to the hybrid $\mathrm{Al}_{2} \mathrm{O}_{3}+\mathrm{CuO}$ nanoparticles. The variations in thermal conductivity results in case of mono and hybrid NCPCMs are due to the nanoparticles size, morphology, den- 
sity, thermal conductivity and dispersion stability into the NCPCMs. The $\mathrm{Al}_{2} \mathrm{O}_{3}$ and $\mathrm{TiO}_{2}$ nanoparticles have the smaller size and density and higher surface area compared to $\mathrm{CuO}$ nanoparticles. Therefore, they have more stronger degree of homogenization and dispersion rate into the $\mathrm{RT}-35 \mathrm{HC}$. Thenceforth, the combination of $\mathrm{Al}_{2} \mathrm{O}_{3}+\mathrm{CuO}$ hybrid nanoparticles having different thermophysical properties reveal the finer dispersion stability. Further more, the boundary layer of thermal resistance of nanoparticles and lattice molecules of PCM contribute a major factor in variation of thermal conductivity results [58]. Generally, there exists two major factors that cause the enhanced phenomenon of thermal conductance within the NCPCMs. Firstly, higher thermal conductivity of the nanoparticles and secondly the motion of the nanoparticles in NCPCMs in liquid-phase which causes a quasi-convection phenomenon [29, 8].

\subsection{Specific heat capacity analysis}

The specific heat capacity results of RT-35HC and NCPCMs are shown in Figure 12 for solid and liquid phases as a function of temperature from $10^{\circ} \mathrm{C}$ to $60^{\circ} \mathrm{C}$. Since the specific heat capacity has the less effect in total thermal energy storage due to low thermal energy storage density in sensible heat storage phase. Regardless, specific heat capacity influences additional effects in the total heat stored by a PCM within the storage temperature range of storage which is calculated using Equation 4 as follows:

$$
Q=\int_{T_{i}}^{T_{m}} m C_{p} \cdot d t+m \alpha_{m} \Delta H_{m}+\int_{T_{m}}^{T_{f}} m C_{p} . d t
$$

where, $Q(\mathrm{~J})$ is the quantity of total heat stored, $T_{i}\left({ }^{\circ} \mathrm{C}\right), T_{m}\left({ }^{\circ} \mathrm{C}\right)$ and $T_{f}\left({ }^{\circ} \mathrm{C}\right)$ are the initial, melting and final temperatures, respectively, $m(\mathrm{~kg})$ mass of the heat storage medium, $C_{p}$ $(\mathrm{J} / \mathrm{kg} . \mathrm{K})$ is the specific heat capacity, $\alpha_{m}$ is the faction of melted mass and $\Delta H_{m}(\mathrm{~J} / \mathrm{kg})$ is the heat of fusion per unit mass. From Equation 4 , it is important to investigate the specific heat capacity variations with temperature to analysis heat transfer and heat storage performance.

The specific heat capacity of NCPCMs increases gradually with temperature between $14^{\circ} \mathrm{C}$ to $30^{\circ} \mathrm{C}$ in solid-phase (Figure 12a) while it remains constant in liquid-phase (Figure 12b). The presented results of specific heat capacity of both phases showed the good agreement with the previous studies [33, 59, 60]. The specific heat capacities of RT-35HC for solid and liquid phases are obtained of 1.88 and $1.77 \mathrm{~J} / \mathrm{g}^{\circ} \mathrm{C}$, respectively. It can be revealed that with addition of the nanoparticles, the specific heat capacity of NCPCMs increases both in solid and liquid phases. The higher values of specific heat capacities are obtained of 2.61 and 


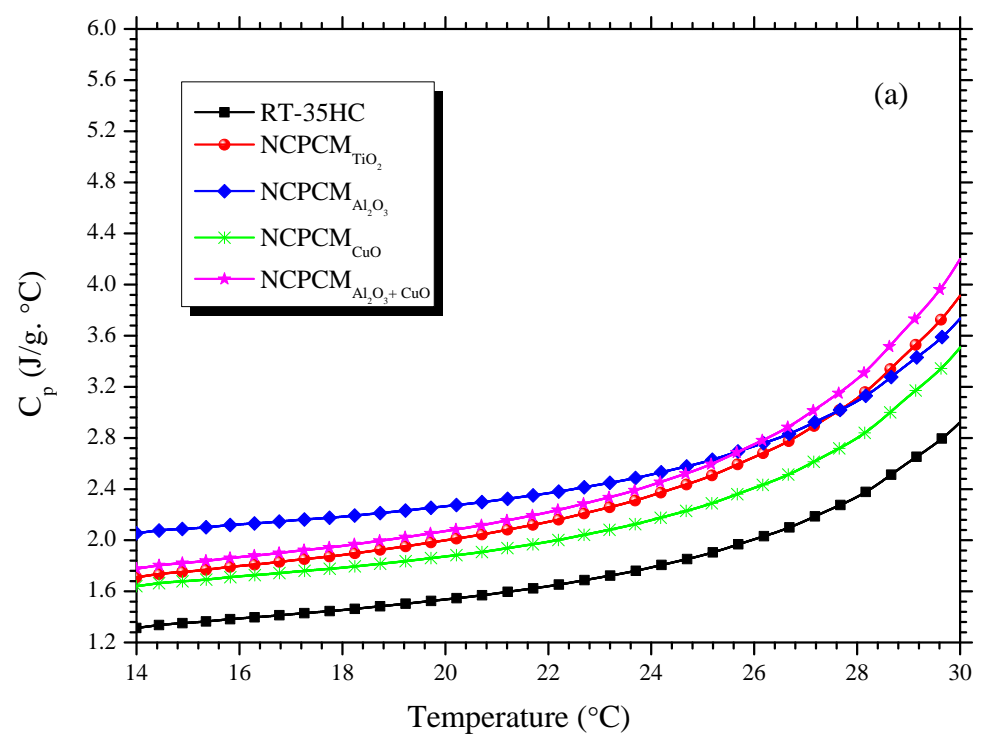

(a)

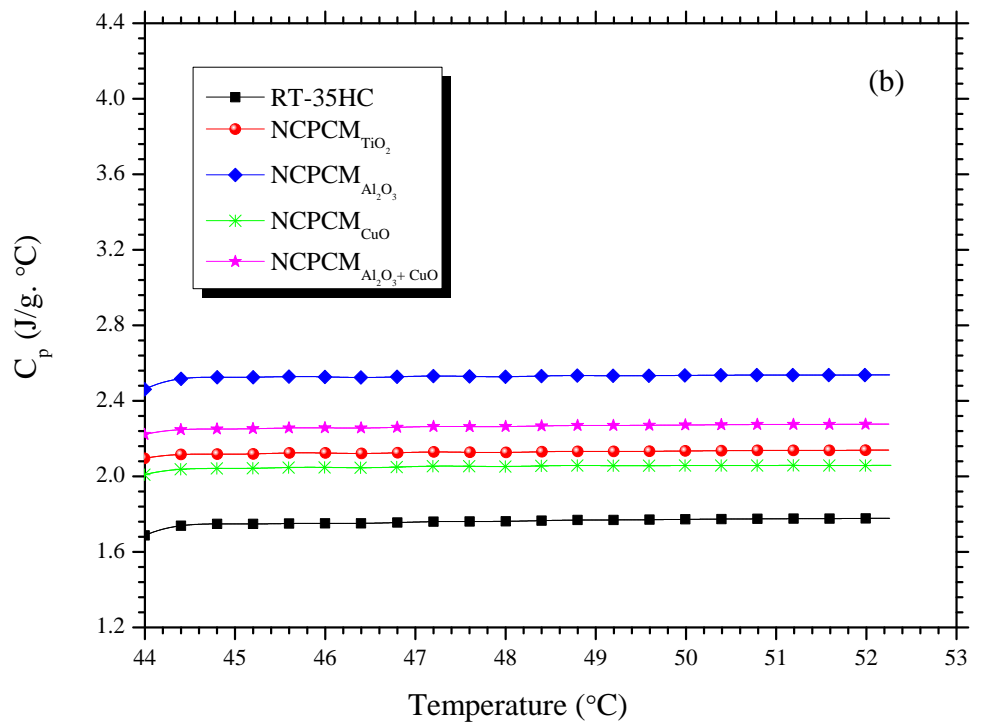

(b)

Figure 12: Specific heat capacity curves of $\mathrm{TiO}_{2}, \mathrm{Al}_{2} \mathrm{O}_{3}, \mathrm{CuO}$ and $\mathrm{RT}$-35HC based mono and hybrid NCPCMs: (a) solid-phase (b) liquid-phase.

$2.53 \mathrm{~J} / \mathrm{g}^{\circ} \mathrm{C}$ at $25^{\circ} \mathrm{C}$ and $50^{\circ} \mathrm{C}$, respectively, for $\mathrm{NCPCM}_{\mathrm{Al}_{2} \mathrm{O}_{3}}$. The polynomial equations are generated for RT-35HC and NCPCMs for solid-phase after fitting the experimental data mentioned in Equation 5 and coefficients are given in Table 4

$$
C_{P}=A T^{3}+B T^{2}+C T+D
$$

Figure 13 represents the comparison of the comparison of specific heat capacities for RT$35 \mathrm{HC}$ and $\mathrm{NCPCMs}$ for $25^{\circ} \mathrm{C}$ and $50^{\circ} \mathrm{C}$ for solid and liquid phases, respectively. Figure $15 \mathrm{a}$ shows that variations in specific heat capacity are significantly depends on the type and specific heat capacity of the nanoparticles. Additionally, the nanoparticles size, density, surface 


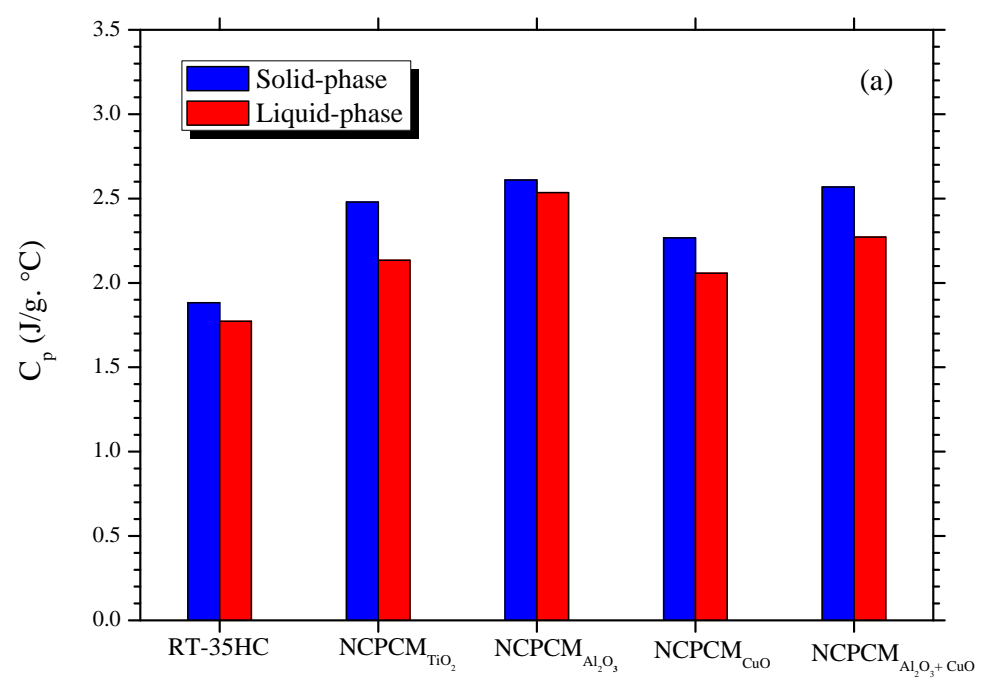

(a)

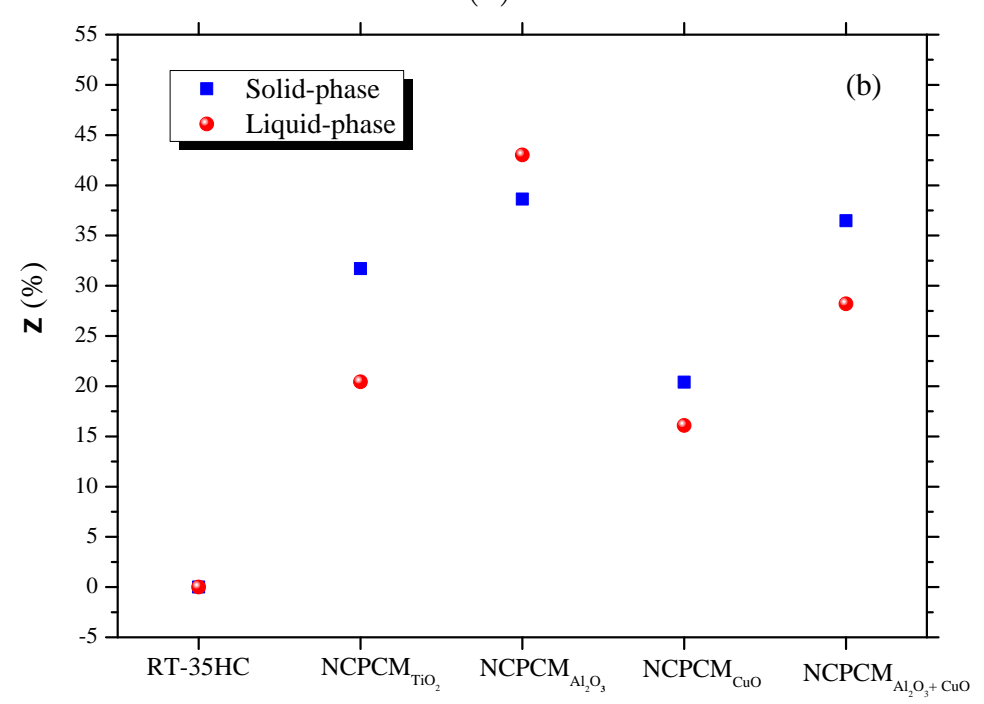

(b)

Figure 13: (a) Comparison of specific heat capacity, (b) specific heat capacity enhancement of $\mathrm{TiO}_{2}, \mathrm{Al}_{2} \mathrm{O}_{3}, \mathrm{CuO}$ and $\mathrm{RT}-35 \mathrm{HC}$ based mono and hybrid NCPCMs.

area and morphology contribute the most prominent effects in enhancement in specific heat capacity. The specific heat capacity enhancement factor $(\zeta)$ is calculated using Equation 6 to evaluate the effect of nanoparticles in enhancement of specific heat capacity:

$$
\zeta=\frac{C_{P_{N C P C M}}-C_{P_{P C M}}}{C_{P_{P C M}}} \times 100
$$

where, $C_{P_{N C P C M}}$ and $C_{P_{P C M}}$ are the specific heat capacity of the NCPCM and PCM, respectively. The maximum enhancements are obtained of $38.62 \%$ is achieved for $\mathrm{NCPCM}_{\mathrm{Al}_{2} \mathrm{O}_{3}}$, whereas it is $36.47 \%$ for $\mathrm{NCPCM}_{\mathrm{Al}_{2} \mathrm{O}_{3}+\mathrm{CuO}}$ in solid phase compared to the RT-35HC.

The enhancement in specific heat capacity is associated with the following reasons: (i) an enhanced anharmonicity of the atomic interaction due to their volume expansion, (ii) 
Table 4: Coefficients of the third-order polynomials in solid-state, $C_{p}\left(\mathrm{~J} / \mathrm{g} \cdot{ }^{\circ} \mathrm{C}\right)$.

\begin{tabular}{|c|c|c|c|c|c|}
\hline & $\mathrm{A}$ & $\mathrm{B}$ & $\mathrm{C}$ & $\mathrm{D}$ & $\mathrm{R}^{2}$ \\
\hline $\mathrm{RT}-35 \mathrm{HC}$ & 0.0006 & -0.0349 & 0.6687 & -2.9832 & 0.9988 \\
\hline $\mathrm{NCPCM}_{\mathrm{TiO}_{2}}$ & 0.0008 & -0.0457 & 0.8701 & -3.8549 & 0.9987 \\
\hline $\mathrm{NCPCM}_{\mathrm{Al}_{2} \mathrm{O}_{3}}$ & 0.0007 & -0.0397 & 0.7606 & -2.8072 & 0.9981 \\
\hline $\mathrm{NCPCM}_{\mathrm{CuO}}$ & 0.0008 & -0.0425 & 0.8092 & -3.5154 & 0.9985 \\
\hline NCPCM $_{\mathrm{Al}_{2} \mathrm{O}_{3}+\mathrm{CuO}}$ & 0.0010 & -0.0567 & 1.0825 & -5.1234 & 0.9981 \\
\hline
\end{tabular}

impurities [61], (iii) the grain boundaries of nanosized materials which possess an excess volume with respect to the perfect crystal lattice and (iv) the high specific surface energies related to the high surface area of the nanoparticles per unit volume [62, 63]. In addition, the morphology of the nanoparticles also influences significantly, since the smaller size nanoparticles provide the larger interfacial surface area per unit mass between solid nanoparticles and surrounding material, thus increase the contribution of interfacial effects in the suspension [64, 65, 66]. The interfacial interaction of solid-solid or solid-liquid may alter phonon spectrum or phonon vibration mode of nanoparticles near the surface area and therefore, change the specific heat capacity of NCPCM 67]. The high specific surficial interface area of nanoparticles can adsorb liquid molecules to its surface which form the liquid layers. These liquid layers constrain the nanoparticles and alter their free-boundary surface atoms into the non-free interior atoms [62, 67]. Therefore, the variation in specific heat capacity of NCPCMs is because of the varied Gibbs free energy of the nanoparticles and liquid layers.

\subsection{IRT analysis}

The IR thermographic images of mono and hybrid NCPCMs are shown in Figure 14 which presents the surface temperature distribution during the melting process at different time steps. The melting stages of $\mathrm{NCPCM}_{\mathrm{Al}_{2} \mathrm{O}_{3}}, \mathrm{NCPCM}_{\mathrm{CuO}}$ and $\mathrm{NCPCM}_{\mathrm{Al}_{2} \mathrm{O}_{3}+\mathrm{CuO}}$ can be seen clearly at each time step, labelled as $(\mathrm{X}),(\mathrm{Y})$ and $(\mathrm{Z})$, respectively, as shown in Figure 14a. The change in temperature of mono and hybrid NCPCMs can be observed from the temperature scale which indicates the lower to higher temperature variations from blue to red colours, respectively. The uniform melting of each sample is observed while heating at constant temperature. The quick flow away and shrinkage is observed in $\mathrm{NCPCM}_{C u O}$, shown in $14 \mathrm{f}$. This phenomenon during phase change from solid-to-liquid causes to lose its shape-stability completely. In case of hybrid $\mathrm{NCPCM}_{\mathrm{Al}_{2} \mathrm{O}_{3}+\mathrm{CuO}}$, uniform phase transition is observed with slight shrinkage and flow away due to the heating-impact effect. Since, the NCPCMs only contain the 1 wt.\% of $\mathrm{Al}_{2} \mathrm{O}_{3}+\mathrm{CuO}$, therefore only slight shrinkage is 
observed. It has been reported that the flow away and shrinkage level decrease with the increase of the loading of nanoparticles. The melting process of $\mathrm{NCPCM}_{\mathrm{Al}_{2} \mathrm{O}_{3}+\mathrm{CuO} \text { shows }}$ that it does not melt completely till at 35 min and surface temperature of hybrid NCPCM is lower than the mono NCPCM. This reveals that the best heat transfer performance due to thermal properties and thermal stability. The enhancement in hybrid $\mathrm{NCPCM}_{\mathrm{Al}_{2} \mathrm{O}_{3}+\mathrm{CuO}}$ is due to the uniform and homogeneous dispersion of $\mathrm{Al}_{2} \mathrm{O}_{3}$ and $\mathrm{CuO}$ nanoparticles in $\mathrm{RT}$ $35 \mathrm{HC}$, which increase the viscosity and shape-stability. Moreover, the thermographic images

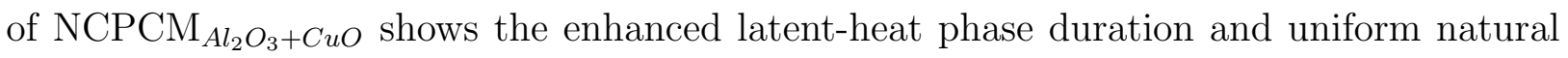
convection heat transfer which can be used in thermal management systems for electronics.

\subsection{Transient thermal analysis}

The transient thermal analysis was carried out by investigating the melting and cooling processes of pure RT-35HC and NCPCMs, as shown in Figure 15 at a power level of 4 W. All samples were poured into a copper made heat sink after sonication to ensure the homogeneous dispersion of nanoparticles. The purpose of using the heat sink in current study, was to investigate the real time thermal response of NCPCMs compared to pure PCM. Since the heat sink has been widely used as heat exchanger that transfers the heat generated inside the electronics towards the ambient through a fluid medium. RT-35HC and NCPCMs were used as fluid medium inside the heat sink as passive cooling medium.

\subsubsection{Melting process}

The melting curves of RT-35HC, $\mathrm{NCPCM}_{\mathrm{TiO}_{2}}, \mathrm{NCPCM}_{\mathrm{Al}_{2} \mathrm{O}_{3}}, \mathrm{NCPCM}_{\mathrm{CuO}}$ and $\mathrm{NCPCM}_{\mathrm{Al}_{2} \mathrm{O}_{3}+\mathrm{CuO}}$ are shown in Figures 15a. It can be seen from melting process that there is rapid increase of temperature linearly in all samples up to the first 20min without showing any phase change. Heat transfer occurs in sensible heat transfer mode because of temperature gradient and specific heat capacity of the samples before melting starts. In addition, the heat transfer depends on the thermal conductivity of the samples. The quicker heating rate was observed for NCPCMs because of higher thermal conductivity. Since the loading content is constant in each sample, thus the variation in average heat sink base temperature is very small. Specific heat capacity of each sample also contribute a major role in total heat transfer rate. In second stage, NCPCMs started melting and a large amount of heat was absorbed because of latent-heat of fusion. Thus, the heat sink base temperature increased slowly which eventually enhanced the thermal performance of NCPCMs based heat sink, used for passive 


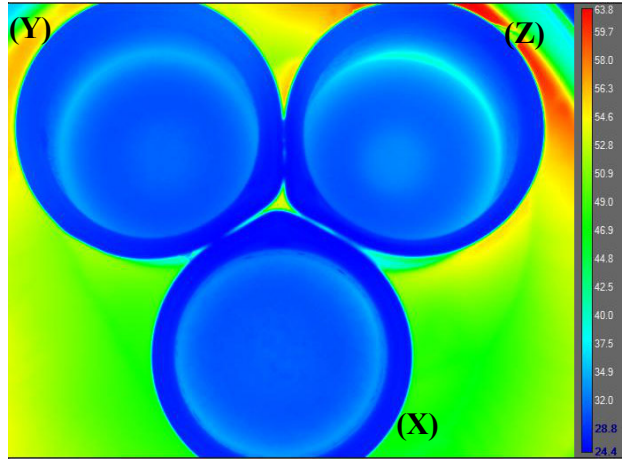

(a) 5 min

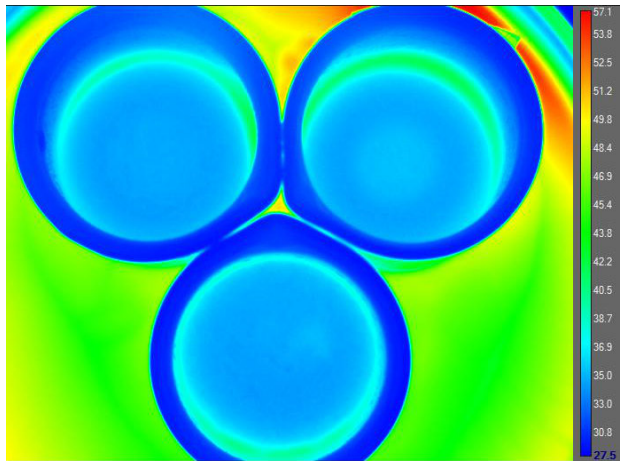

(c) $15 \min$

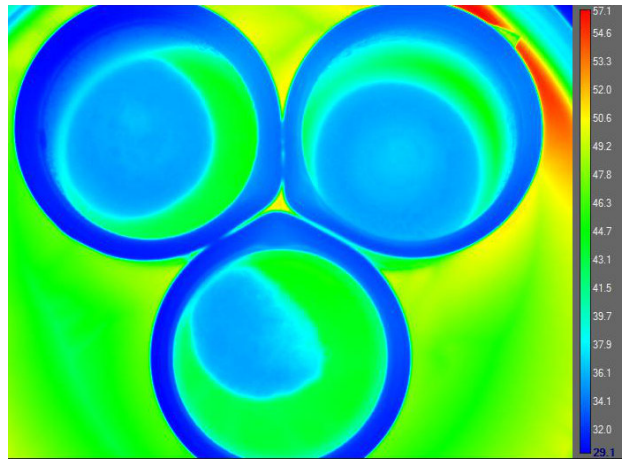

(e) $25 \mathrm{~min}$

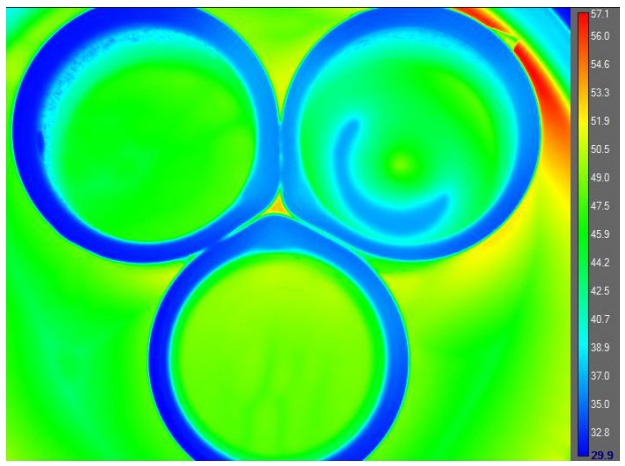

(g) $35 \mathrm{~min}$

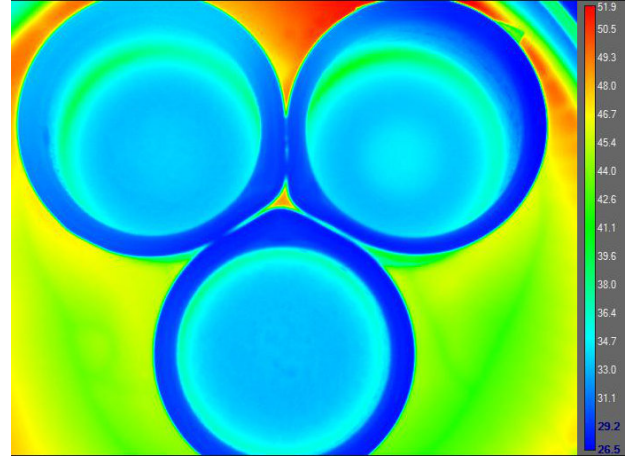

(b) $10 \mathrm{~min}$

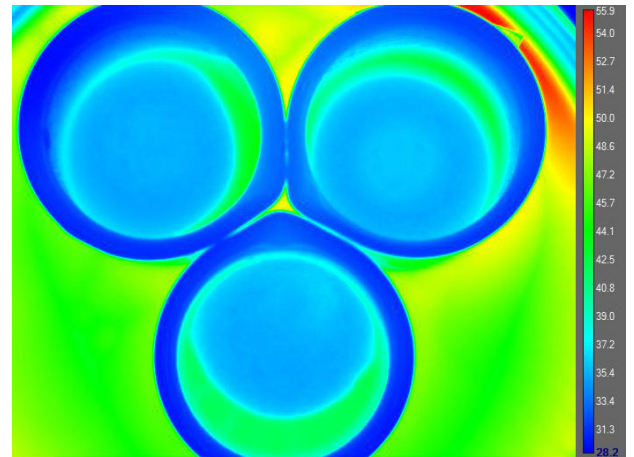

(d) $20 \mathrm{~min}$

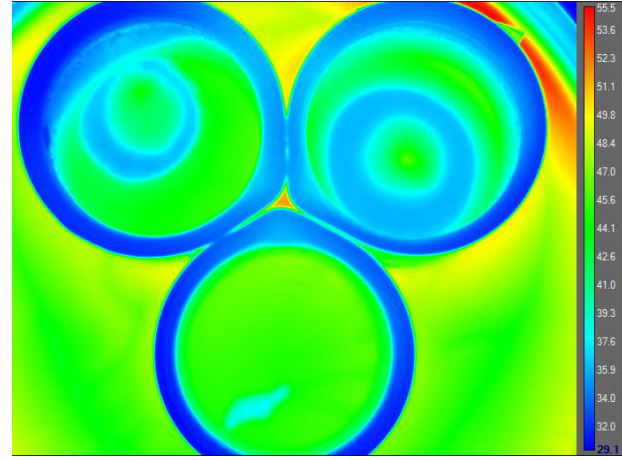

(f) $30 \mathrm{~min}$

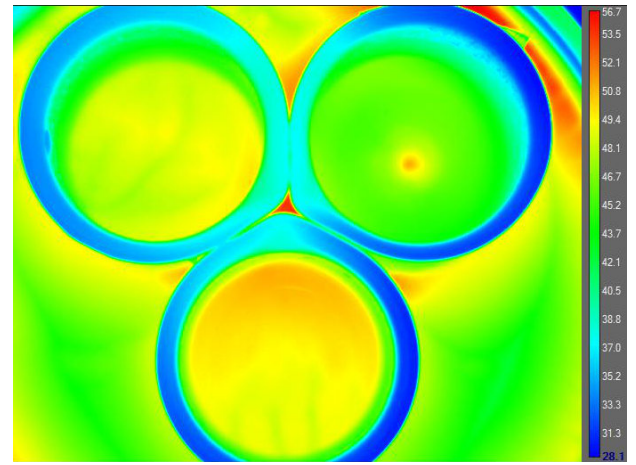

(h) $40 \mathrm{~min}$

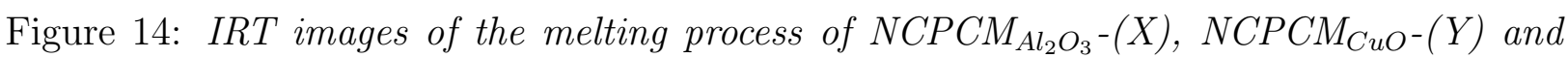

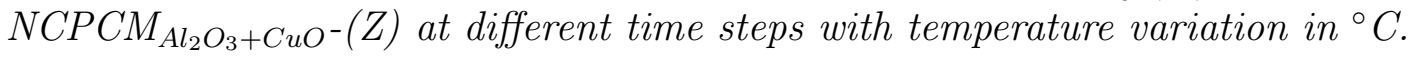

cooling of electronic devices. The viscosity of composite PCM increases directly by adding 
of composite PCM also depends on the viscosity of NCPCMs at loading content of 1.0wt.\%. The lower temperature rise of heat sink base is beneficial for the thermal management of electronic devices, Li-ion battery and PV modules.

\subsubsection{Cooling process}

The cooling curves of RT-35HC, $\mathrm{NCPCM}_{\mathrm{TiO}_{2}}, \mathrm{NCPCM}_{\mathrm{Al}_{2} \mathrm{O}_{3}}, \mathrm{NCPCM}_{\mathrm{CuO}}$ and $\mathrm{NCPCM}_{\mathrm{Al}_{2} \mathrm{O}_{3}+\mathrm{CuO}}$ are shown in Figure 15b. The transient temperature variation of heat sink base temperature can be divided into three different stages: pre-sensible cooling, latent-heat of solidification and post-sensible cooling. It can be observed closely that NCPCMs have the faster decrement in temperature compared to the pure PCM. The higher rate of temperature decrease reflects the higher thermal conductivity enhancement of NCPCMs due the addition of $\mathrm{TiO}_{2}, \mathrm{Al}_{2} \mathrm{O}_{3}, \mathrm{CuO}$ nanoparticles. During the cooling process, the base temperature decreased sharply and NCPCMs released their sensible heat to cool down up to their congealing temperature. Further, the NCPCMs started solidifying process due to their latentheat of solidification at ambient temperature through natural convection phenomenon. The minimum temperatures of $22.36^{\circ} \mathrm{C}, 21.54^{\circ} \mathrm{C}, 20.99^{\circ} \mathrm{C}, 19.24^{\circ} \mathrm{C}$ and $20.52^{\circ} \mathrm{C}$ were recorded for RT-35HC, $\mathrm{NCPCM}_{\mathrm{TiO}_{2}}, \mathrm{NCPCM}_{\mathrm{Al}_{2} \mathrm{O}_{3}}, \mathrm{NCPCM}_{\mathrm{CuO}}$ and $\mathrm{NCPCM}_{\mathrm{Al}_{2} \mathrm{O}_{3}+\mathrm{CuO}}$, respectively, after $150 \mathrm{~min}$ of cooling process. The reduction in heat sink base temperature was achieved of $3.67 \%, 6.13 \%, 13.95 \%$ and $8.23 \%$ for $\mathrm{NCPCM}_{\mathrm{TiO}_{2}}, \mathrm{NCPCM}_{\mathrm{Al}_{2} \mathrm{O}_{3}}, \mathrm{NCPCM}_{\mathrm{CuO}}$

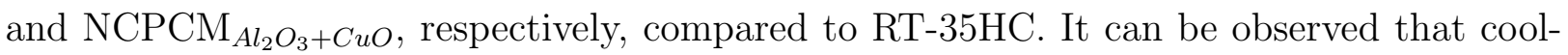
ing process was longer than the melting process. Also, phase change process of PCM and NCPCMs was more prolonged while cooling process than the melting process. The reason behind of such irregular melting and cooling phenomenon depends on the heating/cooling rate. While cooling process, the melting rate was higher than the cooling process which took the less time to change the solid-liquid phase than the cooling process while phase transition from liquid to solid phase. The results revealed that the addition of nanoparticles improve the cooling rate of PCM result in decrease the average temperature heat sink base. Thus, NCPCMs filled heat sink improves the cooling efficiency and enhance the reliability of electronic devices.

\section{Conclusions}

The current experimental study explores the physical, chemical and thermal properties of metallic oxide nanoparticles $\left(\mathrm{TiO}_{2}, \mathrm{Al}_{2} \mathrm{O}_{3}\right.$ and $\left.\mathrm{CuO}\right)$ based nanocomposite phase change 


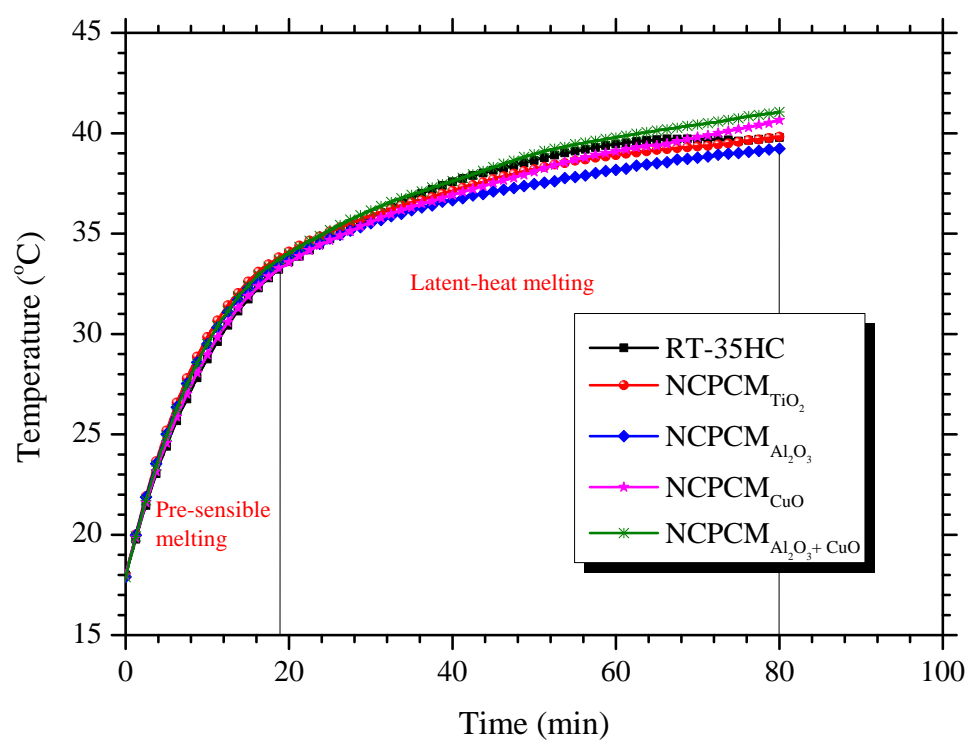

(a)

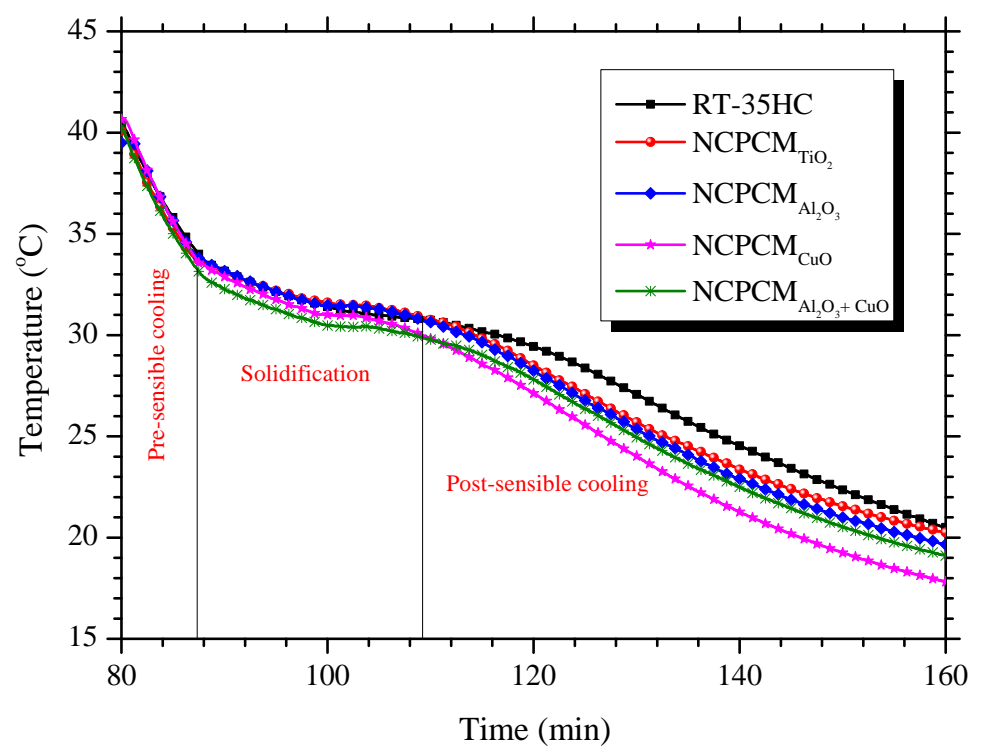

(b)

Figure 15: (a) Melting process and (b) solidifying process of $\mathrm{TiO}_{2}, \mathrm{Al}_{2} \mathrm{O}_{3}, \mathrm{CuO}$ and $\mathrm{RT}$ $35 \mathrm{HC}$ based mono and hybrid NCPCMs.

materials (NCPCMs). Material characteristic techniques such as ESEM, FT-IR, TGA, DSC and TCA were used to investigate optimum thermal properties for efficient thermal management systems and solar thermal energy storage. The critical findings are summarized as follows:

- The surface morphological analysis of ESEM revealed the uniform dispersion and presence of $\mathrm{TiO}_{2}, \mathrm{Al}_{2} \mathrm{O}_{3}$ and $\mathrm{CuO}$ nanoparticles in RT-35HC. Furthermore, XRD patterns confirmed the presence of all the nanoparticles in both mono and hybrid NCPCMs. 
- The FT-IR spectrum presents that there is no chemical interaction between the nanoparticles and RT-35HC, and no peak shifting was observed. Hence, there is only physical interaction of $\mathrm{TiO}_{2}, \mathrm{Al}_{2} \mathrm{O}_{3}$ and $\mathrm{CuO}$ nanoparticles with $\mathrm{RT}-35 \mathrm{HC}$.

- The TGA and DTG analysis explored that all mono and hybrid NCPCMs did not loss the chemical and thermal stability. In fact, the addition of $\mathrm{TiO}_{2}, \mathrm{Al}_{2} \mathrm{O}_{3}$ and $\mathrm{CuO}$ nanoparticles improved the thermal and chemical stability of RT-35HC. More-

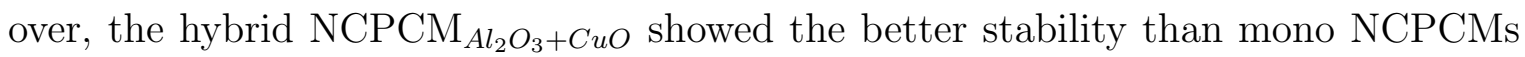
$\left(\mathrm{NCPCM}_{\mathrm{TiO}_{2}}, \mathrm{NCPCM}_{\mathrm{Al}_{2} \mathrm{O}_{3}}\right.$ and $\left.\mathrm{NCPCM}_{\mathrm{CuO}}\right)$.

- Overall, the phase-change enthalpy of melting/solidification was decreased with the addition of $\mathrm{TiO}_{2}, \mathrm{Al}_{2} \mathrm{O}_{3}$ and $\mathrm{CuO}$ nanoparticles in both mono and hybrid NCPCMs. The latent-heat of melting of 235.84, 234.79, 233.9 and $228.46 \mathrm{~J} / \mathrm{g}$ were obtained for of $\mathrm{NCPCM}_{\mathrm{TiO}_{2}}, \mathrm{NCPCM}_{\mathrm{Al}_{2} \mathrm{O}_{3}}, \mathrm{NCPCM}_{\mathrm{CuO}}$ and $\mathrm{NCPCM}_{\mathrm{Al}_{2} \mathrm{O}_{3}+\mathrm{CuO}}$, respectively. Similarly, the latent-heat of solidification of 239.30, 241.65, 235.4 and 229.34 were obtained for of $\mathrm{NCPCM}_{\mathrm{TiO}_{2}}, \mathrm{NCPCM}_{\mathrm{Al}_{2} \mathrm{O}_{3}}, \mathrm{NCPCM}_{\mathrm{CuO}}$ and $\mathrm{NCPCM}_{\mathrm{Al}_{2} \mathrm{O}_{3}+\mathrm{CuO}}$, respectively. The maximum deviation in peak melting temperatures were observed of $-1.14 \%$ for

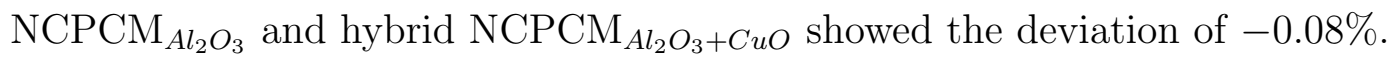

- The thermal conductivity result predicted that hybrid $\mathrm{NCPCM}_{\mathrm{Al}_{2} \mathrm{O}_{3}+\mathrm{CuO}}$ mass percentage ratio of $75 \% / 25 \%$ showed the maximum thermal conductivity of $0.328 \mathrm{~W} / \mathrm{m} . \mathrm{K}$ with thermal conductivity enhancement of $53.7 \%$ compared to RT-35HC.

- The increasing trend in the specific heat capacity of NCPCMs were observed. The maximum enhancements were obtained of $38.62 \%$ for $\mathrm{NCPCM}_{\mathrm{Al}_{2} \mathrm{O}_{3}}$, whereas it was $36.47 \%$ for hybrid $\mathrm{NCPCM}_{\mathrm{Al}_{2} \mathrm{O}_{3}+\mathrm{CuO}}$ in solid phase compared to the pure RT-35HC. However, the enhancement in specific heat capacity depends on the nanoparticles size, type, density, surface area and morphology of the nanoparticles.

- The uniform melting and temperature distribution were observed from IR thermographic images of mono and hybrid NCPCMs. The enhancement in melting time was obtained with hybrid $\mathrm{NCPCM}_{\mathrm{Al}_{2} \mathrm{O}_{3}+\mathrm{CuO}}$ because of uniform dispersion of $\mathrm{Al}_{2} \mathrm{O}_{3}$ and $\mathrm{CuO}$ nanoparticles having varying densities and particle sizes. The reduction in heat sink base temperature was achieved of $3.67 \%, 6.13 \%, 13.95 \%$ and $8.23 \%$ for $\mathrm{NCPCM}_{\mathrm{TiO}_{2}}, \mathrm{NCPCM}_{\mathrm{Al}_{2} \mathrm{O}_{3}}, \mathrm{NCPCM}_{\mathrm{CuO}}$ and $\mathrm{NCPCM}_{\mathrm{Al}_{2} \mathrm{O}_{3}+\mathrm{CuO}}$, respectively, compared to RT-35HC. 
The current study finally concludes that newly synthesized metallic oxide nanoparticles based hybrid NCPCMs have the better improvement in the thermal energy storage properties compared to the mono NCPCMs, which ultimately enhance the rate of heat transfer in conjugate heat transfer mode. Thereby, hybrid NCPCMs can be successfully used in passive thermal management systems for electronic devices, Li-ion batteries, photovoltaics modules and direct utilization in solar thermal energy storage and distribution in natural environment.

\section{Acknowledgement}

This research is facilitated by the Faculty of Engineering, University of Nottingham, UK research infrastructure. The first author (Adeel Arshad) acknowledges the University of Nottingham for awarding him the Faculty of Engineering Research Excellence PhD Scholarship to pursue a Ph.D. research program. The authors acknowledge the use of facilities at Nanoscale and Microscale Research Centre of the University of Nottingham supported by Engineering and Physical Sciences Research Council [grant number EP/L022494/1]. 


\section{References}

[1] F. Bosselman, J. B. Eisen, J. Rossi, D. B. Spence, J. L. Weaver, Energy, economics and the environment: cases and materials, ENERGY, ECONOMICS AND THE ENVIRONMENT: CASES AND MATERIALS, Foundation Press.

[2] R. Quadrelli, S. Peterson, The energy-climate challenge: Recent trends in CO2 emissions from fuel combustion, Energy Policy 35 (11) (2007) 5938-5952. doi:10.1016/j . enpol.2007.07.001.

[3] F. Jotzo, P. J. Burke, P. J. Wood, A. Macintosh, D. I. Stern, Decomposing the 2010 global carbon dioxide emissions rebound, Nature Climate Change 2 (4) (2012) 213-214. doi:10.1038/nclimate1450.

[4] O. Akashi, T. Hanaoka, T. Masui, M. Kainuma, Halving global GHG emissions by 2050 without depending on nuclear and CCS, Climatic Change 123 (3-4) (2013) 611-622. doi:10.1007/s10584-013-0942-x

[5] L. Shi, Y. Hu, Y. He, Magneto-responsive thermal switch for remote-controlled locomotion and heat transfer based on magnetic nanofluid, Nano Energy 71 (2020) 104582. doi:10.1016/j.nanoen.2020.104582.

[6] L. Shi, Y. Hu, Y. Bai, Y. He, Dynamic tuning of magnetic phase change composites for solar-thermal conversion and energy storage, Applied Energy 263 (2020) 114570. doi:10.1016/j.apenergy.2020.114570.

[7] L. Shi, X. Wang, Y. Hu, Y. He, Investigation of photocatalytic activity through photothermal heating enabled by fe3o4/TiO2 composite under magnetic field, Solar Energy 196 (2020) 505-512. doi:10.1016/j.solener.2019.12.053

[8] A. Arshad, M. Jabbal, Y. Yan, Preparation and characteristics evaluation of mono and hybrid nano-enhanced phase change materials (NePCMs) for thermal management of microelectronics, Energy Conversion and Management 205 (2020) 112444. doi: $10.1016 / \mathrm{j}$. enconman.2019.112444.

[9] A. R. M. Siddique, S. Mahmud, B. V. Heyst, A comprehensive review on a passive (phase change materials) and an active (thermoelectric cooler) battery thermal management system and their limitations, Journal of Power Sources 401 (2018) 224-237. doi:10.1016/j.jpowsour.2018.08.094. 
[10] R. Gulfam, P. Zhang, Z. Meng, Advanced thermal systems driven by paraffin-based phase change materials - a review, Applied Energy 238 (2019) 582-611. doi:10.1016/ j.apenergy.2019.01.114.

[11] A. Arshad, H. M. Ali, M. Ali, S. Manzoor, Thermal performance of phase change material (PCM) based pin-finned heat sinks for electronics devices: Effect of pin thickness and PCM volume fraction, Applied Thermal Engineering 112 (2017) 143-155. doi:10.1016/j.applthermaleng.2016.10.090.

[12] H. M. Ali, A. Arshad, Experimental investigation of n-eicosane based circular pin-fin heat sinks for passive cooling of electronic devices, International Journal of Heat and Mass Transfer 112 (2017) 649-661. doi:10.1016/j.ijheatmasstransfer.2017.05. 004 .

[13] A. Arshad, H. M. Ali, W.-M. Yan, A. K. Hussein, M. Ahmadlouydarab, An experimental study of enhanced heat sinks for thermal management using n-eicosane as phase change material, Applied Thermal Engineering 132 (2018) 52-66. doi: 10.1016/j . applthermaleng.2017.12.066.

[14] A. Arshad, H. M. Ali, S. Khushnood, M. Jabbal, Experimental investigation of PCM based round pin-fin heat sinks for thermal management of electronics: Effect of pinfin diameter, International Journal of Heat and Mass Transfer 117 (2018) 861-872. doi:10.1016/j.ijheatmasstransfer.2017.10.008.

[15] H. M. Ali, M. J. Ashraf, A. Giovannelli, M. Irfan, T. B. Irshad, H. M. Hamid, F. Hassan, A. Arshad, Thermal management of electronics: An experimental analysis of triangular, rectangular and circular pin-fin heat sinks for various PCMs, International Journal of Heat and Mass Transfer 123 (2018) 272-284. doi:10.1016/j.ijheatmasstransfer. 2018.02 .044 .

[16] H. M. Ali, A. Arshad, M. M. Janjua, W. Baig, U. Sajjad, Thermal performance of LHSU for electronics under steady and transient operations modes, International Journal of Heat and Mass Transfer 127 (2018) 1223-1232. doi:10.1016/j.ijheatmasstransfer. 2018.06 .120 .

[17] H. M. Ali, A. Arshad, M. Jabbal, P. Verdin, Thermal management of electronics devices with PCMs filled pin-fin heat sinks: A comparison, International Journal of Heat and 
Mass Transfer 117 (2018) 1199-1204. doi:10.1016/j.ijheatmasstransfer.2017.10. 065 .

[18] M. Al-Jethelah, S. Ebadi, K. Venkateshwar, S. Tasnim, S. Mahmud, A. Dutta, Charging nanoparticle enhanced bio-based PCM in open cell metallic foams: An experimental investigation, Applied Thermal Engineering 148 (2019) 1029-1042. doi:10.1016/j. applthermaleng.2018.11.121.

[19] J. M. Mahdi, S. Lohrasbi, E. C. Nsofor, Hybrid heat transfer enhancement for latentheat thermal energy storage systems: A review, International Journal of Heat and Mass Transfer 137 (2019) 630-649. doi:10.1016/j.ijheatmasstransfer.2019.03.111.

[20] A. Allahbakhsh, M. Arjmand, Graphene-based phase change composites for energy harvesting and storage: State of the art and future prospects, Carbon 148 (2019) 441480. doi:10.1016/j.carbon.2019.04.009.

[21] J. P. Tarelho, M. P. S. dos Santos, J. A. Ferreira, A. Ramos, S. Kopyl, S. O. Kim, S. Hong, A. Kholkin, Graphene-based materials and structures for energy harvesting with fluids - a review, Materials Today 21 (10) (2018) 1019-1041. doi:10.1016/j. mattod.2018.06.004

[22] A. N. Keshteli, M. Sheikholeslami, Nanoparticle enhanced PCM applications for intensification of thermal performance in building: A review, Journal of Molecular Liquids 274 (2019) 516-533. doi:10.1016/j.molliq.2018.10.151.

[23] A. Arshad, M. Jabbal, Y. Yan, J. Darkwa, The micro-/nano-pcms for thermal energy storage systems: A state of art review, International Journal of Energy Research 43 (11) (2019) 5572-5620. arXiv:https://onlinelibrary.wiley.com/doi/pdf/10. 1002/er.4550, doi:10.1002/er.4550.

URL https://onlinelibrary.wiley.com/doi/abs/10.1002/er . 4550

[24] C. Liu, Z. Rao, J. Zhao, Y. Huo, Y. Li, Review on nanoencapsulated phase change materials: Preparation, characterization and heat transfer enhancement, Nano Energy 13 (2015) 814-826. doi:10.1016/j.nanoen.2015.02.016.

[25] F. Rodríguez-Cumplido, E. Pabón-Gelves, F. Chejne-Jana, Recent developments in the synthesis of microencapsulated and nanoencapsulated phase change materials, Journal of Energy Storage 24 (2019) 100821. doi:10.1016/j.est.2019.100821. 
[26] E. M. Shchukina, M. Graham, Z. Zheng, D. G. Shchukin, Nanoencapsulation of phase change materials for advanced thermal energy storage systems, Chemical Society Reviews 47 (11) (2018) 4156-4175. doi:10.1039/c8cs00099a.

[27] M. Eugeni, H. Elahi, F. Fune, L. Lampani, F. Mastroddi, G. P. Romano, P. Gaudenzi, Numerical and experimental investigation of piezoelectric energy harvester based on flag-flutter, Aerospace Science and Technology 97 (2020) 105634. doi:10.1016/j. ast. 2019.105634

[28] H. Elahi, M. Eugeni, P. Gaudenzi, Design and performance evaluation of a piezoelectric aeroelastic energy harvester based on the limit cycle oscillation phenomenon, Acta Astronautica 157 (2019) 233-240. doi:10.1016/j.actaastro.2018.12.044.

[29] A. Babapoor, G. Karimi, Thermal properties measurement and heat storage analysis of paraffinnanoparticles composites phase change material: Comparison and optimization, Applied Thermal Engineering 90 (2015) 945-951. doi:10.1016/j.applthermaleng. 2015.07 .083

[30] A. Babapoor, G. Karimi, S. Sabbaghi, Thermal characteristic of nanocomposite phase change materials during solidification process, Journal of Energy Storage 7 (2016) 7481. doi:10.1016/j.est.2016.05.006.

[31] M. Nourani, N. Hamdami, J. Keramat, A. Moheb, M. Shahedi, Thermal behavior of paraffin-nano-al2o3 stabilized by sodium stearoyl lactylate as a stable phase change material with high thermal conductivity, Renewable Energy 88 (2016) 474-482. doi: $10.1016 / j . r e n e n e .2015 .11 .043$

[32] M. Nourani, N. Hamdami, J. Keramat, A. Moheb, M. Shahedi, Preparation of a stable nanocomposite phase change material (NCPCM) using sodium stearoyl lactylate (SSL) as the surfactant and evaluation of its stability using image analysis, Renewable Energy 93 (2016) 404-411. doi:10.1016/j.renene.2016.02.073.

[33] M. Chieruzzi, A. Miliozzi, T. Crescenzi, L. Torre, J. M. Kenny, A new phase change material based on potassium nitrate with silica and alumina nanoparticles for thermal energy storage, Nanoscale Research Letters 10 (1). doi:10.1186/s11671-015-0984-2.

[34] R. Sharma, P. Ganesan, V. Tyagi, H. Metselaar, S. Sandaran, Thermal properties and heat storage analysis of palmitic acid-TiO 2 composite as nano-enhanced organic 
phase change material (NEOPCM), Applied Thermal Engineering 99 (2016) 1254-1262. doi:10.1016/j.applthermaleng.2016.01.130

[35] D. Yang, S. Shi, L. Xiong, H. Guo, H. Zhang, X. Chen, C. Wang, X. Chen, Paraffin/palygorskite composite phase change materials for thermal energy storage, Solar Energy Materials and Solar Cells 144 (2016) 228-234. doi:10.1016/j.solmat.2015. 09.002 .

[36] X. Li, Y. Zhou, H. Nian, X. Zhang, O. Dong, X. Ren, J. Zeng, C. Hai, Y. Shen, Advanced nanocomposite phase change material based on calcium chloride hexahydrate with aluminum oxide nanoparticles for thermal energy storage, Energy \& Fuels 31 (6) (2017) 6560-6567. doi:10.1021/acs.energyfuels.7b00851.

[37] S. Sami, N. Etesami, Improving thermal characteristics and stability of phase change material containing tio2 nanoparticles after thermal cycles for energy storage, Applied Thermal Engineering 124 (2017) 346-352.

[38] M. Bashar, K. Siddiqui, Experimental investigation of transient melting and heat transfer behavior of nanoparticle-enriched PCM in a rectangular enclosure, Journal of Energy Storage 18 (2018) 485-497. doi:10.1016/j.est.2018.06.006.

[39] B. Praveen, S. Suresh, Experimental study on heat transfer performance of neopentyl glycol/CuO composite solid-solid PCM in TES based heat sink, Engineering Science and Technology, an International Journal 21 (5) (2018) 1086-1094. doi:10.1016/j. jestch.2018.07.010.

[40] C. Li, Q. Li, L. Cong, F. jiang, Y. Zhao, C. Liu, Y. Xiong, C. Chang, Y. Ding, $\mathrm{MgO}$ based composite phase change materials for thermal energy storage: The effects of $\mathrm{MgO}$ particle density and size on microstructural characteristics as well as thermophysical and mechanical properties, Applied Energy 250 (2019) 81-91. doi: $10.1016 / \mathrm{j}$. apenergy.2019.04.094.

[41] S. K. Sahoo, M. K. Das, P. Rath, Application of TCE-PCM based heat sinks for cooling of electronic components: A review, Renewable and Sustainable Energy Reviews 59 (2016) 550-582. doi:10.1016/j.rser.2015.12.238.

[42] A. Arshad, M. Jabbal, Y. Yan, D. Reay, A review on graphene based nanofluids: 
Preparation, characterization and applications, Journal of Molecular Liquids 279 (2019) 444-484. doi:10.1016/j.molliq.2019.01.153.

[43] A. Asadi, I. M. Alarifi, V. Ali, H. M. Nguyen, An experimental investigation on the effects of ultrasonication time on stability and thermal conductivity of MWCNT-water nanofluid: Finding the optimum ultrasonication time, Ultrasonics Sonochemistry 58 (2019) 104639. doi:10.1016/j.ultsonch.2019.104639.

[44] Ta instruments sdt-q600 simultaneous tga / dsc, artisan technology group, usa, accessed: 01/10/2019.

URL https://www.artisantg.com/Scientific/74393-1/TA_Instruments_SDT_ Q600_Simultaneous_TGA_DSC

[45] Dsc 2500, ta instruments, uk, accessed: 01/10/2019.

URL https://www.tainstruments.com/dsc-2500/

[46] Tci thermal conductivity analyzer, c-therm technologies ltd. canada, accessed: $01 / 10 / 2019$.

URL https://ctherm.com/products/tci_thermal_conductivity/

[47] G. W. Burns, M. Scroger, G. Strouse, M. Croarkin, W. Guthrie, Temperatureelectromotive force reference functions and tables for the letter-designated thermocouple types based on the its-90, NASA STI/Recon Technical Report N 93.

[48] S. J. Kline, Describing uncertainty in single sample experiments, Mech. Engineering 75 (1953) 3-8.

[49] M. Saterlie, H. Sahin, B. Kavlicoglu, Y. Liu, O. Graeve, Particle size effects in the thermal conductivity enhancement of copper-based nanofluids, Nanoscale Research Letters 6 (1) (2011) 217. doi:10.1186/1556-276x-6-217.

[50] W. Evans, R. Prasher, J. Fish, P. Meakin, P. Phelan, P. Keblinski, Effect of aggregation and interfacial thermal resistance on thermal conductivity of nanocomposites and colloidal nanofluids, International Journal of Heat and Mass Transfer 51 (5-6) (2008) 1431-1438. doi:10.1016/j.ijheatmasstransfer.2007.10.017.

[51] F. Bakhtiari, E. Darezereshki, One-step synthesis of tenorite ( $\mathrm{CuO})$ nano-particles from 
cu4 (SO4) (OH) 6 by direct thermal-decomposition method, Materials Letters 65 (2) (2011) 171-174. doi:10.1016/j.matlet.2010.09.071.

[52] M. Faisal, S. B. Khan, M. M. Rahman, A. Jamal, A. Umar, Ethanol chemi-sensor: Evaluation of structural, optical and sensing properties of $\mathrm{CuO}$ nanosheets, Materials Letters 65 (9) (2011) 1400-1403. doi:10.1016/j.matlet.2011.02.013

[53] Y. Chen, W. Luo, J. Wang, J. Huang, Enhanced thermal conductivity and durability of a paraffin wax nanocomposite based on carbon-coated aluminum nanoparticles, The Journal of Physical Chemistry C 121 (23) (2017) 12603-12609. doi:10.1021/acs. jpcc.7b02651.

[54] F. Yavari, H. R. Fard, K. Pashayi, M. A. Rafiee, A. Zamiri, Z. Yu, R. Ozisik, T. BorcaTasciuc, N. Koratkar, Enhanced thermal conductivity in a nanostructured phase change composite due to low concentration graphene additives, The Journal of Physical Chemistry C 115 (17) (2011) 8753-8758. doi:10.1021/jp200838s.

[55] H. Liu, X. Wang, D. Wu, Fabrication of graphene/TiO2/paraffin composite phase change materials for enhancement of solar energy efficiency in photocatalysis and latent heat storage, ACS Sustainable Chemistry \& Engineering 5 (6) (2017) 4906-4915. doi:10.1021/acssuschemeng.7b00321.

[56] H. Tian, W. Wang, J. Ding, X. Wei, M. Song, J. Yang, Thermal conductivities and characteristics of ternary eutectic chloride/expanded graphite thermal energy storage composites, Applied Energy 148 (2015) 87-92. doi:10.1016/j.apenergy.2015.03. 020.

[57] J. Wang, H. Xie, Z. Xin, Y. Li, L. Chen, Enhancing thermal conductivity of palmitic acid based phase change materials with carbon nanotubes as fillers, Solar Energy 84 (2) (2010) 339-344. doi:10.1016/j.solener.2009.12.004.

[58] O. Mahian, L. Kolsi, M. Amani, P. Estellé, G. Ahmadi, C. Kleinstreuer, J. S. Marshall, M. Siavashi, R. A. Taylor, H. Niazmand, S. Wongwises, T. Hayat, A. Kolanjiyil, A. Kasaeian, I. Pop, Recent advances in modeling and simulation of nanofluid flows-part i: Fundamentals and theory, Physics Reports 790 (2019) 1-48. doi: $10.1016 / j \cdot$ physrep.2018.11.004. 
[59] M. Mehrali, S. T. Latibari, M. Mehrali, T. M. I. Mahlia, E. Sadeghinezhad, H. S. C. Metselaar, Preparation of nitrogen-doped graphene/palmitic acid shape stabilized composite phase change material with remarkable thermal properties for thermal energy storage, Applied Energy 135 (2014) 339-349. doi:10.1016/j . apenergy . 2014.08.100.

[60] A. A. Aydın, A. Aydın, High-chain fatty acid esters of 1-hexadecanol for low temperature thermal energy storage with phase change materials, Solar Energy Materials and Solar Cells 96 (2012) 93-100. doi:10.1016/j.solmat.2011.09.013.

[61] E. Hellstern, H. J. Fecht, Z. Fu, W. L. Johnson, Structural and thermodynamic properties of heavily mechanically deformed ru and AlRu, Journal of Applied Physics 65 (1) (1989) 305-310. doi:10.1063/1.342541.

[62] B.-X. Wang, L.-P. Zhou, X.-F. Peng, Surface and size effects on the specific heat capacity of nanoparticles, International Journal of Thermophysics 27 (1) (2006) 139-151. doi:10.1007/s10765-006-0022-9.

[63] L. Wang, Z. Tan, S. Meng, D. Liang, G. Li, Enhancement of molar heat capacity of nanostructured al2o3, Journal of Nanoparticle Research 3 (5/6) (2001) 483-487. doi:10.1023/a:1012514216429.

[64] E. V. Timofeeva, J. L. Routbort, D. Singh, Particle shape effects on thermophysical properties of alumina nanofluids, Journal of Applied Physics 106 (1) (2009) 014304. doi:10.1063/1.3155999.

[65] H. Xie, J. Wang, T. Xi, Y. Liu, F. Ai, Q. Wu, Thermal conductivity enhancement of suspensions containing nanosized alumina particles, Journal of Applied Physics 91 (7) (2002) 4568-4572. doi:10.1063/1.1454184.

[66] H. D. Koca, S. Doganay, A. Turgut, I. H. Tavman, R. Saidur, I. M. Mahbubul, Effect of particle size on the viscosity of nanofluids: A review, Renewable and Sustainable Energy Reviews 82 (2018) 1664-1674. doi:10.1016/j.rser.2017.07.016.

[67] Z. Le-Ping, W. Bu-Xuan, P. Xiao-Feng, X.-Z. Du, Y. Yong-Ping, On the specific heat capacity of cuo nanofluid, Advances in Mechanical Engineering 02 (2010) 1-4. doi: $10.1155 / 2010 / 172085$. 